\title{
Nano/Micro-Patterning of Semiconductors by Site Selective Chemical Etching Using Noble Metals as Catalyst
}

\author{
Sachiko Ono* and Hidetaka Asoh \\ Department of Applied Chemistry, Faculty of Engineering, Kogakuin University, Tokyo \\ Japan
}

\section{Introduction}

Controlled silicon structures on the micron to nanometer order have received much attention owing to their potential applications in various fields such as electrochemical, optoelectrical, and biological sciences. Although the techniques commonly used in fabricating nano-/microstructured silicon are conventional lithographic techniques using a resist mask with an optical, electron, or X-ray beam, chemical etching is also widely used in silicon micromachining. Three-dimensional silicon microstructures such as pillars, tubes, and macropores are fabricated by electrochemical etching in hydrofluoric acid (HF). This is a promising technique for the micromachining of silicon (Lehmann \& Foll, 1990; Kleimann et al 2001; Matthias et al 2004).

Among three-dimensional silicon microstructures, silicon with a regular porous structure of the order of submicrons to nanometres, which is normally fabricated by electrochemical etching, has been studied intensively from the viewpoint of both basic research and commercial applications over the past few decades (Lehmann, 2002; Asoh and Ono, 2007, 2010). In the present chapter, nano-fabrication of semiconductor surfaces such as Si and GaAs by the combination of site selective chemical etching using various noble metals as catalyst and colloidal crystal templating is described with focusing on the difference in etching properties of each metal species. By applying this technique, ordered hexagonal arrays of crystalline Au nanodots on silicon were also obtained.

A novel technique for fabricating porous silicon without applying an external bias, socalled metal-assisted chemical etching, was proposed (Li \& Bohn, 2000). According to their report, a porous silicon layer can be formed easily and efficiently by immersing silicon wafers coated with a noble metal (i.e. $\mathrm{Au}, \mathrm{Pt}$, or $\mathrm{Au}-\mathrm{Pd}$ ) in $\mathrm{HF}$ mixed with hydrogen peroxide $\left(\mathrm{H}_{2} \mathrm{O}_{2}\right)$ solution. A mechanism involving a localized electrochemical process has been proposed to explain the mechanism of metal-assisted chemical etching as follows (Li \& Bohn, 2000):

Cathode reaction (at noble metal surface as a local cathode):

* Corresponding Author 


$$
\begin{gathered}
\mathrm{H}_{2} \mathrm{O}_{2}+2 \mathrm{H}^{+} \rightarrow 2 \mathrm{H}_{2} \mathrm{O}+2 \mathrm{~h}^{+}, \\
2 \mathrm{H}^{+} \rightarrow \mathrm{H}_{2} \uparrow+2 \mathrm{~h}^{+} .
\end{gathered}
$$

Anode reaction (at silicon surface):

$$
\begin{gathered}
\mathrm{Si}+4 \mathrm{~h}^{+}+4 \mathrm{HF} \rightarrow \mathrm{SiF}_{4}+4 \mathrm{H}^{+}, \\
\mathrm{SiF}_{4}+2 \mathrm{HF} \rightarrow \mathrm{H}_{2} \mathrm{SiF}_{6} .
\end{gathered}
$$

Overall reaction:

$$
\mathrm{Si}+\mathrm{H}_{2} \mathrm{O}_{2}+6 \mathrm{HF} \rightarrow 2 \mathrm{H}_{2} \mathrm{O}+\mathrm{H}_{2} \mathrm{SiF}_{6}+\mathrm{H}_{2} \uparrow .
$$

In other words, when oxidants $\left(\mathrm{H}_{2} \mathrm{O}_{2}\right)$ are reduced on the surfaces of noble metal catalysts, positive holes $\left(\mathrm{h}^{+}\right)$are generated. After the removal of electrons from metal particles, the potential of the metal shifts towards a positive value to a level enabling the injection of $h^{+}$ into the silicon substrate. Finally, anodic oxidation and the dissolution of silicon take place in the chemical etchant containing HF.

Various types of silicon microstructures such as deep straight nanopores and helical silicon nanopores have been prepared by metal-assisted chemical etching (Yae et al, 2003; Tsujino \& Matsumura, 2005a; Tsujino \& Matsumura, 2005b). These microstructures are expected to be used for improving the light-emitting properties and conversion efficiency of solar cells. The formation of porous silicon by metal-assisted chemical etching can proceed in the presence of not only $\mathrm{Au}, \mathrm{Pt}$, and $\mathrm{Au}-\mathrm{Pd}$ particles but also other noble metals such as $\mathrm{Ag}$ and $\mathrm{Pd}$.

Recently, we have reported the fabrication of ordered $\mathrm{Si}$, GaAs and InP microstructures such as convex arrays and nanopore patterns with regular periodicity of the order of micrometres by combining colloidal crystal templating and site-selective chemical etching using patterned noble-metal thin films as catalysts (Asoh et al, 2007a; Asoh et al, 2007b; Arai et al, 2008; Yasukawa et al, 2010). In addition, by using a shape-controlled Pt-Pd thin film as a catalyst, we have fabricated silicon microwells containing Pt-Pd thin films (Asoh et al, 2008a). We carry out a preliminary study to examine the effect of noble metal catalyst species on the morphology of macroporous silicon prepared by metal-assisted chemical etching (Asoh et al, 2009). We mainly focus on the correlation between the morphology of etched semiconductor microstructures, etching rate, and catalyst species in the present chapter.

\section{Colloidal crystal templating}

Concerning the application using two-dimensional (2D) colloidal crystals, "natural lithography", which has been proposed by Deckman and Dunsmuir in 1982, has attracted attention due to relatively easy process in comparison with conventional lithography. Based on such process, uniformly sized microstructures could be produced on a substrate using a monolayer coating of colloidal spheres instead of a conventional resist. In recent years, these techniques, which are often called "colloidal lithography" or "nanosphere lithography", have been reported on the nano-/micro-fabrication or nano-/micro-patterning on a wide variety of solid substrates including semiconductors, metals and ceramics. In the case of the use of 2D colloidal crystals as a physical mask, however, the target position for lithography 
is restricted to only interspaces among spheres. Although low ability to fabricate highquality two-dimensional (2D) colloidal crystals, which limits the application fields for resultant patterns, is often pointed out as one of the drawbacks of such lithographic techniques, the regularity of colloidal crystals with wafer-scale sizes has been improving year by year (Jiang \& McFarland, 2004). More recently, an efficient self-assembly technique for fabricating centimeter-sized single-domain 2D colloidal crystals under capillary forces within a wedge-shaped cell has been reported (Sun et al, 2010). For more details on the different strategies for the self-assembly into ordered 2D crystalline arrays and their applications, see the review papers (Velev and Kaler, 2000; Xia et al, 2000).

\section{Formation of microstructures on silicon using colloidal crystal templating, hydrophobic treatment and electroless metal plating}

The principle of pattern transfer for fabricating convex and hole arrays is schematically shown in Fig. 1 (Asoh et al, 2007a; Asoh et al, 2007b; Ono et al, 2007; Arai et al, 2008). Figures $2 \mathrm{a}$ and $2 \mathrm{~b}$ show SEM images of Ag particles deposited on a silicon substrate (Asoh et al, 2007a). In the case without a mask, the fine Ag particles spread out over the whole silicon surface, as shown in Fig. 2a. The sizes and distribution of the particles on the silicon surface are in agreement with previous results (Tsujino \& Matsumura, 2005a). On the other hand, when a $2 \mathrm{D}$ hexagonal array of polystyrene spheres of $3 \mu \mathrm{m}$ diameter was used as a direct

a)
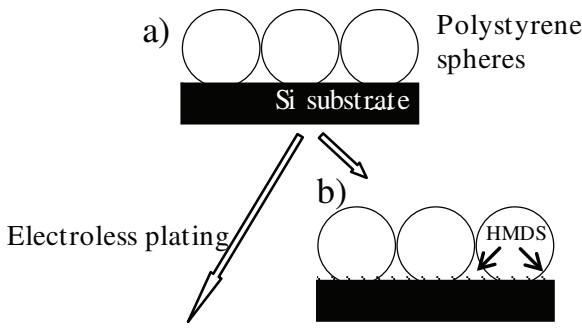

b)

c)

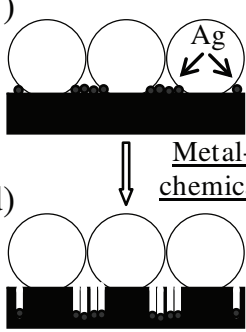

e)

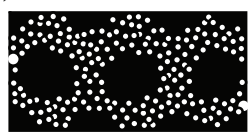

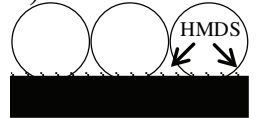

f) $\int$ Electroless plating

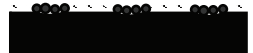

letching

g)

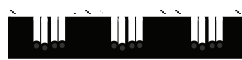

h)

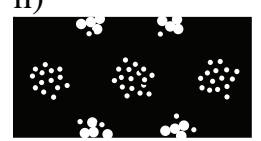

Fig. 1. Schematic model of site-selective chemical etching of silicon: (a) colloidal crystals on silicon substrate; (b) HMDS coating; (c), (f) electroless plating; (d), (g) chemical etching of silicon using Ag particles as catalyst; (e), (h) top view after removal of colloidal crystals. 
mask during electroless plating (i.e., metal deposition which occur without the use of external electric source), a Ag honeycomb pattern was obtained, as shown in Fig. 2b. Using colloidal crystals as a mask, Ag particles were deposited selectively among the spheres. In other words, selective metal deposition can proceed only on the exposed parts of the silicon surface, which are located in the voids among the spheres on the silicon substrate. This result indicates that colloidal crystals can act as a mask for localized electroless plating in aqueous solution.

The details of the electroless plating process were reported in one of our previous papers (Asoh et al 2007c). In Fig. 2b, the center-to-center distance between the holes in the Ag honeycomb pattern, which was basically determined by the diameter of the polystyrene spheres, was approximately $3 \mu \mathrm{m}$. The framework of the Ag honeycomb pattern was composed of an aggregation of fine Ag particles. The sizes of the Ag particles were mostly between $50 \mathrm{~nm}$ and $100 \mathrm{~nm}$ but were scattered in the range from $10 \mathrm{~nm}$ to $250 \mathrm{~nm}$.

\subsection{Convex arrays of silicon using Ag particles as etching catalyst}

After the deposition of the Ag particles on the silicon substrate, the specimens were immersed in a mixed solution of $\mathrm{HF}$ and $\mathrm{H}_{2} \mathrm{O}_{2}$ to form porous silicon by metal-assisted chemical etching. Figure 2c shows an SEM image of the etched silicon surface using a patterned Ag catalyst. The periodicity of the obtained silicon convex arrays was approximately $3 \mu \mathrm{m}$, corresponding to the diameter of the polystyrene spheres used as a mask for electroless plating. The configuration of silicon convex arrays, which were arranged hexagonally over the entire area of the specimen, has an inverse relation to the honeycomb pattern of the Ag particles, as shown in Fig. 2b. That is, chemical etching proceeds only on the Ag-coated Si surface, in agreement with the proposed mechanism (Li \& Bohn, 2000; Chattopadhyay et al, 2002) and, consequently, the contact area between the polystyrene spheres and the underlying Si substrate has a disklike shape. However, prolonged chemical etching in a HF-containing solution caused the destruction of silicon microstructures owing to the excessive dissolution of the horizontal plane. Nevertheless, deep straight holes that had grown vertically downward from the surface and were deeper than $30 \mu \mathrm{m}$ were found in a fractured cross section as shown in Fig. 3 (Ono et al, 2007). The diameter of the long holes appears to be approximately $100 \mathrm{~nm}$, which is in agreement with the size of the Ag particles. Ag particles were found at the tip of straight long holes as shown in the insert in Fig. 3b, similarly to those described in an earlier report (Tsujino \& Matsumura, 2005a).

\subsection{Hole arrays of silicon using Ag particles as etching catalyst}

To expand the range of applications of ordered silicon microstructures, it is necessary to control the silicon surface morphology. By colloidal crystal templating, it is possible to fabricate negative and positive patterns by changing the configuration of the Ag particles used as a catalyst. To fabricate a metal pattern that is the reverse of the Ag honeycomb pattern shown in Fig. 2b, two-step replication was applied. First, a colloidal crystal mask was formed on the silicon substrate, as described above. Second, specimens were placed in hexamethyldisilazane (HMDS) vapor overnight (Fig. 1b). HMDS is a popular reagent for forming hydrophobic surfaces based on the immobilization of trimethylsilyl groups on the 
surface (Ivanisevic \& Mirkin, 2001; Maccarini et al, 2005), namely, areas of HMDS-coated silicon exhibit hydrophobicity and are thought to inhibit Ag deposition. Finally, electroless plating and chemical etching were conducted as described above (Figs. 1f-h).

Figure $4 \mathrm{a}$ shows the isolated patterns of $\mathrm{Ag}$ particles deposited by selective electroless plating using HMDS-coated silicon. The deposition is restricted to well-defined bare silicon surfaces, and does not occur on the HMDS-coated silicon. This result indicates that the HMDS-coated areas, which are located in the voids among the spheres on the silicon substrate, possess sufficient hydrophobicity and can act as a mask for localized electroless plating in aqueous solution. In Fig. 4a, the center-to-center distance between the island microarrays of Ag particles was approximately $3 \mu \mathrm{m}$. The isolated Ag patterns were composed of an aggregation of Ag particles with sizes in the range of 50-100 nm.
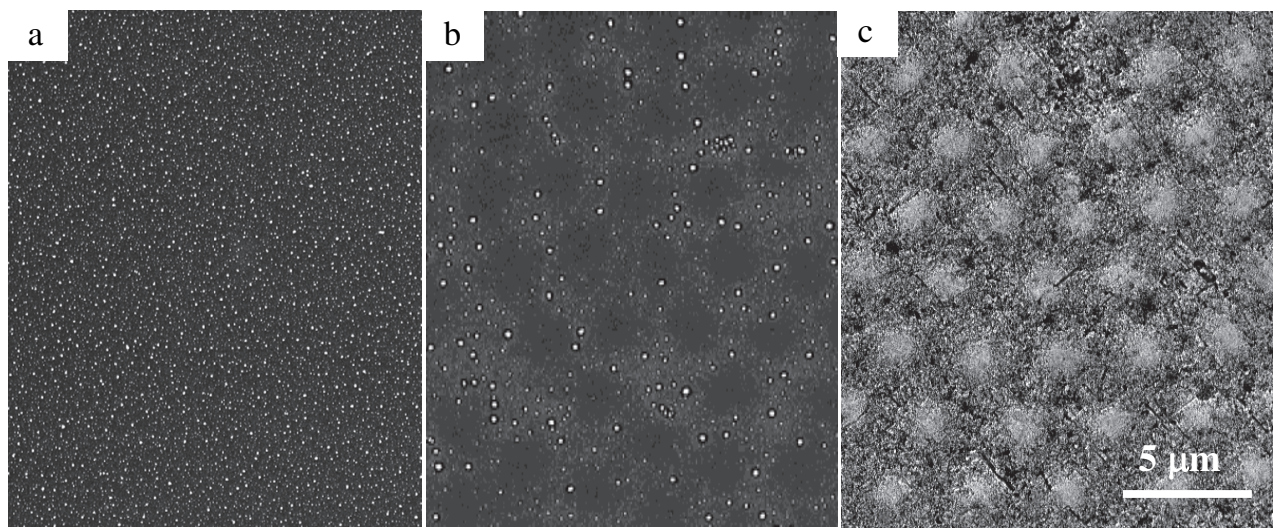

Fig. 2. SEM images of Ag particles deposited on silicon: (a) without mask and (b) with colloidal crystal mask. Electroless plating was conducted in $\mathrm{AgClO}_{4} / \mathrm{NaOH}$ for 20 min. (c) SEM image of surface of silicon etched in $5 \mathrm{~mol} \mathrm{dm}-3 \mathrm{HF} / 1 \mathrm{~mol} \mathrm{dm}^{-3} \mathrm{H}_{2} \mathrm{O}_{2}$ for $1 \mathrm{~min}$.
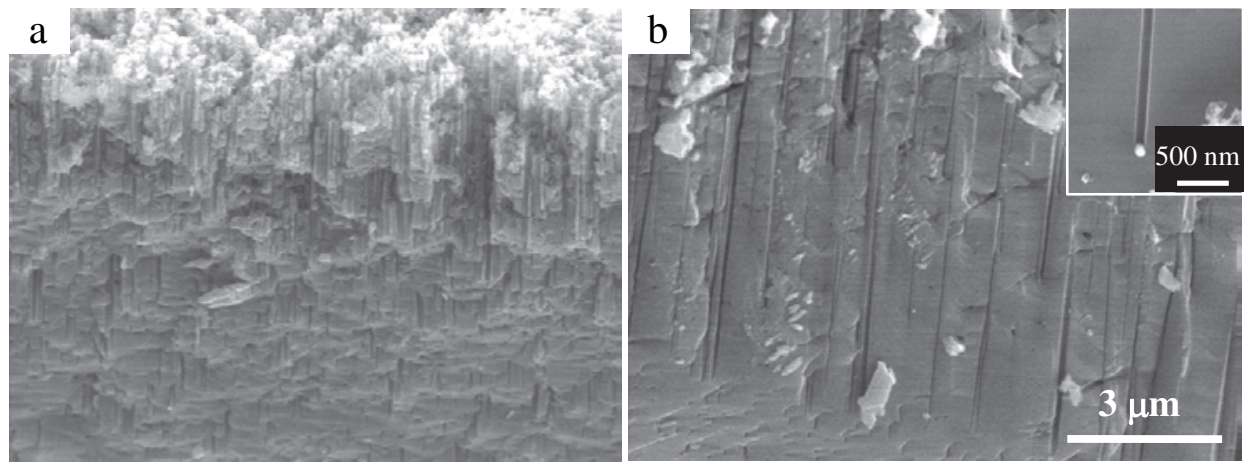

Fig. 3. SEM images of a fractured section of the silicon substrate obtained after etching with the Ag honeycomb pattern shown in Fig. 2 for 30 min: (a) near-surface region and (b) intermediate area revealing deep straight holes that had grown vertically downward from the silicon surface. The insert shows a deep hole with a Ag particle at the tip. 

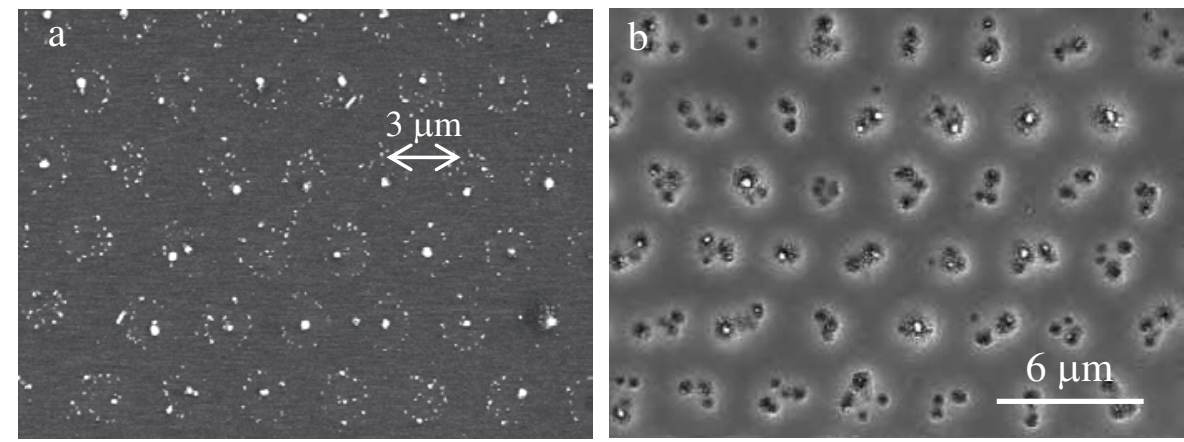

Fig. 4. (a) Isolated patterns of Ag particles formed on silicon and (b) silicon nanohole array. The electroless plating and etching conditions were the same as those for Fig. 2.

Figure $4 \mathrm{~b}$ shows an SEM image of a nanohole array on a silicon substrate. The aggregation of nanoholes with sizes in the range of 50-100 nm was arranged hexagonally over the entire area of the specimen, corresponding to the 2D hexagonal array of polystyrene beads used as the original mask for the formation of the HMDS honeycomb pattern. Some Ag particles, which were detected as bright circular spots, were observed at the bottom of the pores due to the short etching time. The sizes of the particles observed in Fig. $4 \mathrm{~b}$ coincided with those of the deposited Ag particles shown in Fig. 4a. These results indicate that chemical etching proceeds only on the Ag-coated silicon surface, and the consequently the HMDS-coated silicon parts remain in a honeycomb pattern.

Figure 5 shows silicon hole arrays with different periodicity after site-selective chemical etching using isolated Ag patterns (Asoh et al, 2007b; Arai et al, 2008). The magnification of each image was the same. The periodicity of the holes was basically determined by the diameter of the polystyrene spheres used as a mask. In each case, chemical etching proceeds only on the Ag-coated silicon surface, and consequently the areas of HMDS-coated silicon remain in a honeycomb pattern. The shortest hole periodicity, which was attained by the optimization of the etching time, was approximately $200 \mathrm{~nm}$ as shown in Fig. 5d. This indicates that the formation of silicon hole arrays with a periodicity of less than $1 \mu \mathrm{m}$ can be achieved by the process described in this section.

\section{Macroporous silicon formed by metal-assisted chemical etching}

\subsection{Silicon microwells containing Pt-Pd thin films}

The fabrication process of Si microwells is schematically shown in Fig. 6. Silicon substrates were precleaned in $1 \mathrm{wt} \% \mathrm{HF}$ to remove organic contaminants and native oxides. A mixed suspension consisting of equal volumes of a $0.2 \mathrm{wt} \%$ suspension of polystyrene (PS) nanospheres with a diameter of $200 \mathrm{~nm}$ (Polysciences, Inc.) and a $0.5 \mathrm{wt} \%$ suspension of silica microspheres with diameter of $3 \mu \mathrm{m}$ (Bangs Laboratories, Inc.) was dropped on the substrates. The suspension on the substrates was dried in air for more than one day, during which the mixture containing spheres of two different diameters self-assembled into a closepacked structure due to the capillary forces. After the complete evaporation of the solvent, the silicon substrates with binary colloidal crystals formed from the spheres were heated at 
$100{ }^{\circ} \mathrm{C}$ for $1 \mathrm{~h}$ to combine the adjacent PS nanospheres [Fig. 6(a)]. After heating, the silica spheres, which were used as a template, were selectively removed by immersing the specimens in $10 \mathrm{wt} \% \mathrm{HF}$ for $10 \mathrm{~min}$ [Fig. 6(b)] to obtain a PS honeycomb mask. SEM images of the binary colloidal crystals and the PS honeycomb mask are shown in Fig. 7.
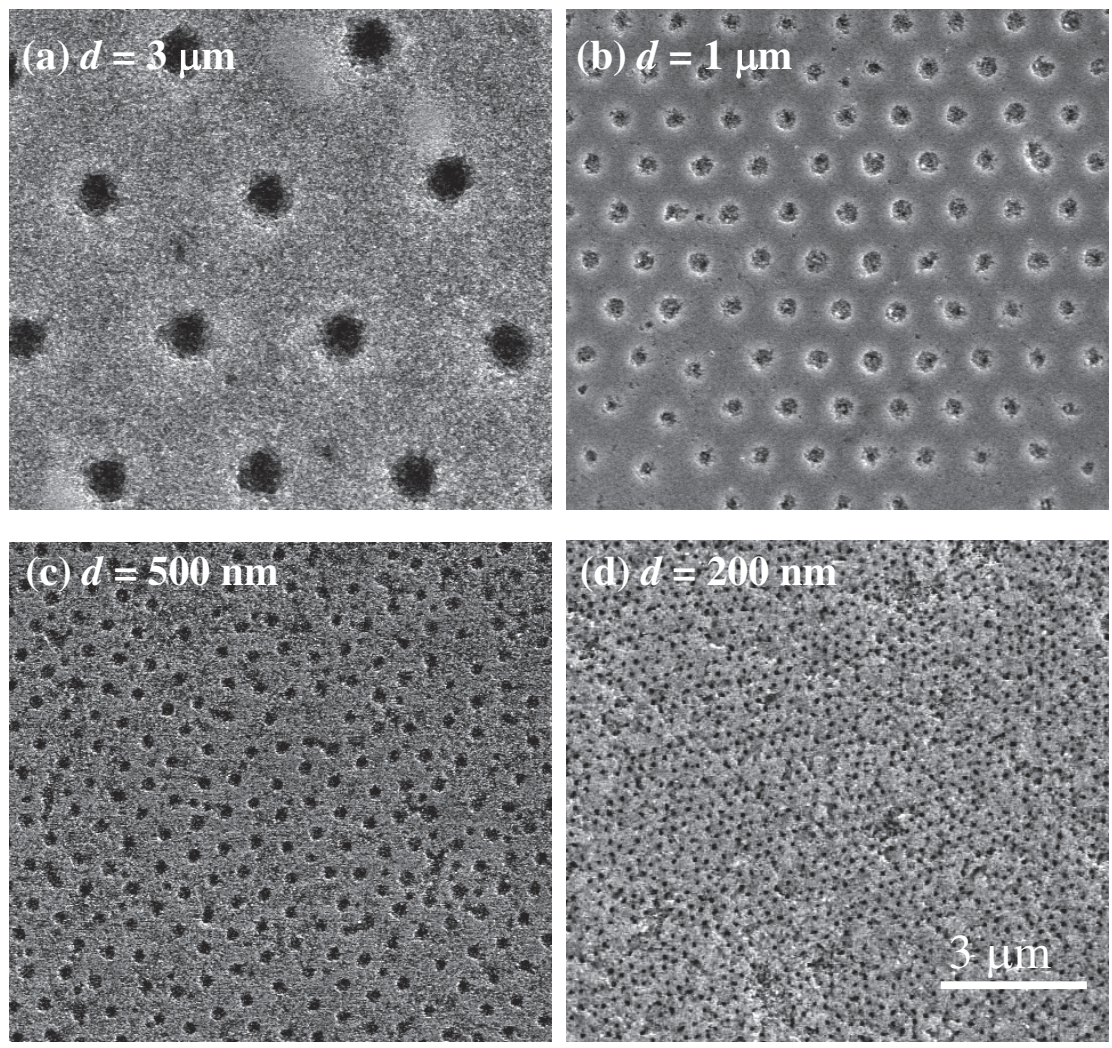

Fig. 5. SEM images of silicon hole arrays after removal of mask: (a) $3 \mu$ m periodicity, (b) 1 $\mu \mathrm{m}$ periodicity, (c) $500 \mathrm{~nm}$ periodicity, and (d) $200 \mathrm{~nm}$ periodicity. Electroless plating was conducted in $10^{-3} \mathrm{~mol} \mathrm{dm}^{-3} \mathrm{AgClO}_{4}$ and $10^{-3} \mathrm{~mol} \mathrm{dm}^{-3} \mathrm{NaOH}$ for $20 \mathrm{~min}$. The chemical etching times in $5 \mathrm{~mol} \mathrm{dm}^{-3} \mathrm{HF} / 1 \mathrm{~mol} \mathrm{dm}^{-3} \mathrm{H}_{2} \mathrm{O}_{2}$ were (a) $5 \mathrm{~min}$ and (b)-(d) $30 \mathrm{~s}$.

Metal thin films were deposited on the silicon substrates by ion sputtering (Hitachi E-1010) using a PS honeycomb mask composed of densely packed PS nanospheres. The sputtering was carried out at a discharge current of $15 \mathrm{~mA}$ in a vacuum with the pressure below $10 \mathrm{~Pa}$ [Fig. 6(c)]. Pt - Pd (80\% Pt and 20\% Pd), Au, and Pt targets were used as sputtering targets. The deposition rates of $\mathrm{Pt}-\mathrm{Pd}, \mathrm{Au}$, and $\mathrm{Pt}$ were 6, 10, and $6 \mathrm{~nm} \mathrm{~min}^{-1}$, respectively. The morphology and thickness of the deposited metal layers were examined by atomic force microscopy (AFM, Digital Instrument NanoScope IIIa). After sputtering, the specimens with locally deposited metal films were etched in a mixed solution of $5 \mathrm{~mol} \mathrm{dm}^{-3} \mathrm{HF}$ and $1 \mathrm{~mol}$ $\mathrm{dm}^{-3} \mathrm{H}_{2} \mathrm{O}_{2}$ at room temperature [Fig. 6(d)]. Finally, the PS honeycomb mask was removed by immersing the specimens in $97 \%$ toluene [Fig. 6(e)]. 
a)

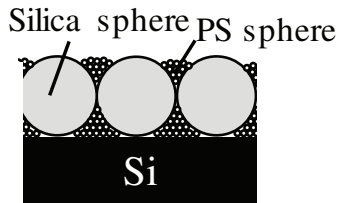

b)

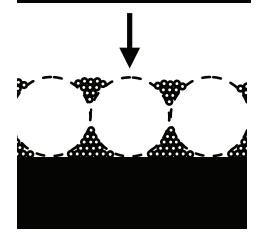

e)

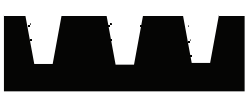

f)

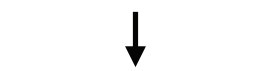

Noble metal catalyst

c)
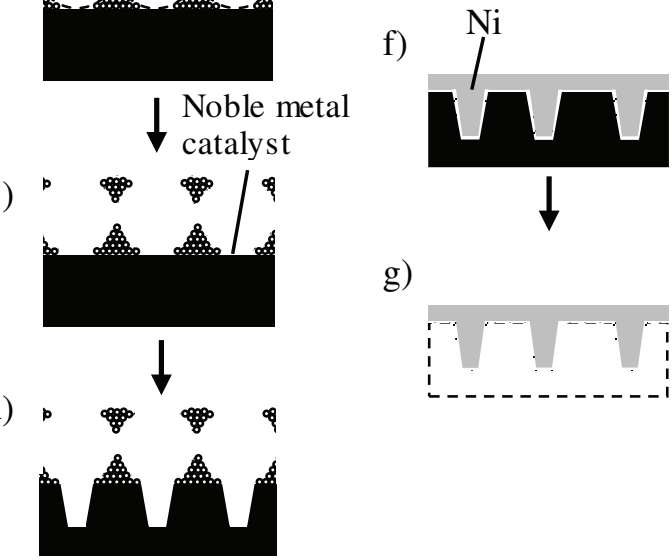

g)

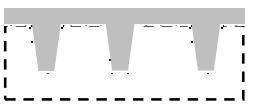

Fig. 6. Schematic model of fabrication of silicon macropore arrays: (a) formation of composite colloidal crystals on silicon substrate, (b) removal of silica sphere, (c) formation of metal catalyst layer, (d) chemical etching of silicon, (e) removal of PS honeycomb mask, (f) electrodeposition of nickel layer, and ( $\mathrm{g}$ ) removal of silicon by immersion of substrate in TMAH.

To examine the morphology of the silicon macropores in the direction of pore depth, a metal replica was prepared by metal plating. After coating the surface of silicon microstructures with metal catalyst layers by ion sputtering, nickel layers were electrodeposited using conventional nickel plating solution [Fig. 6(f)]. Finally, the silicon substrates were selectively removed by immersing the specimens in tetramethyl ammonium hydroxide (TMAH) [Fig. $6(\mathrm{~g})]$. The ordered geometric pattern formed on the silicon substrates was evaluated by scanning electron microscopy (SEM, Hitachi S-4200) and focused ion beam microscopy (FIB, Hitachi FB-2100).

When ion sputtering was carried out using the PS honeycomb mask, isolated circular metal thin films with a diameter of approximately $1.6 \mu \mathrm{m}$ were deposited in the interspaces of the PS mask (Asoh et al, 2008a). Fig. 8(a) shows a typical AFM image of the Pt - Pd thin film arrays deposited on a silicon substrate (Asoh et al, 2009). From the cross-section analysis of the AFM image, the maximum thickness of the Pt - Pd layer deposited by using the PS honeycomb mask after a sputtering time of $5 \mathrm{~min}$ was estimated to be $10-15 \mathrm{~nm}$. The thickness of the deposited layer was less than half the thickness estimated from the 
sputtering rate of $\mathrm{Pt}-\mathrm{Pd}$. The decrease in the deposition thickness is assumed to be caused by the use of the PS honeycomb with a thickness of approximately $2 \mu \mathrm{m}$ during sputtering.
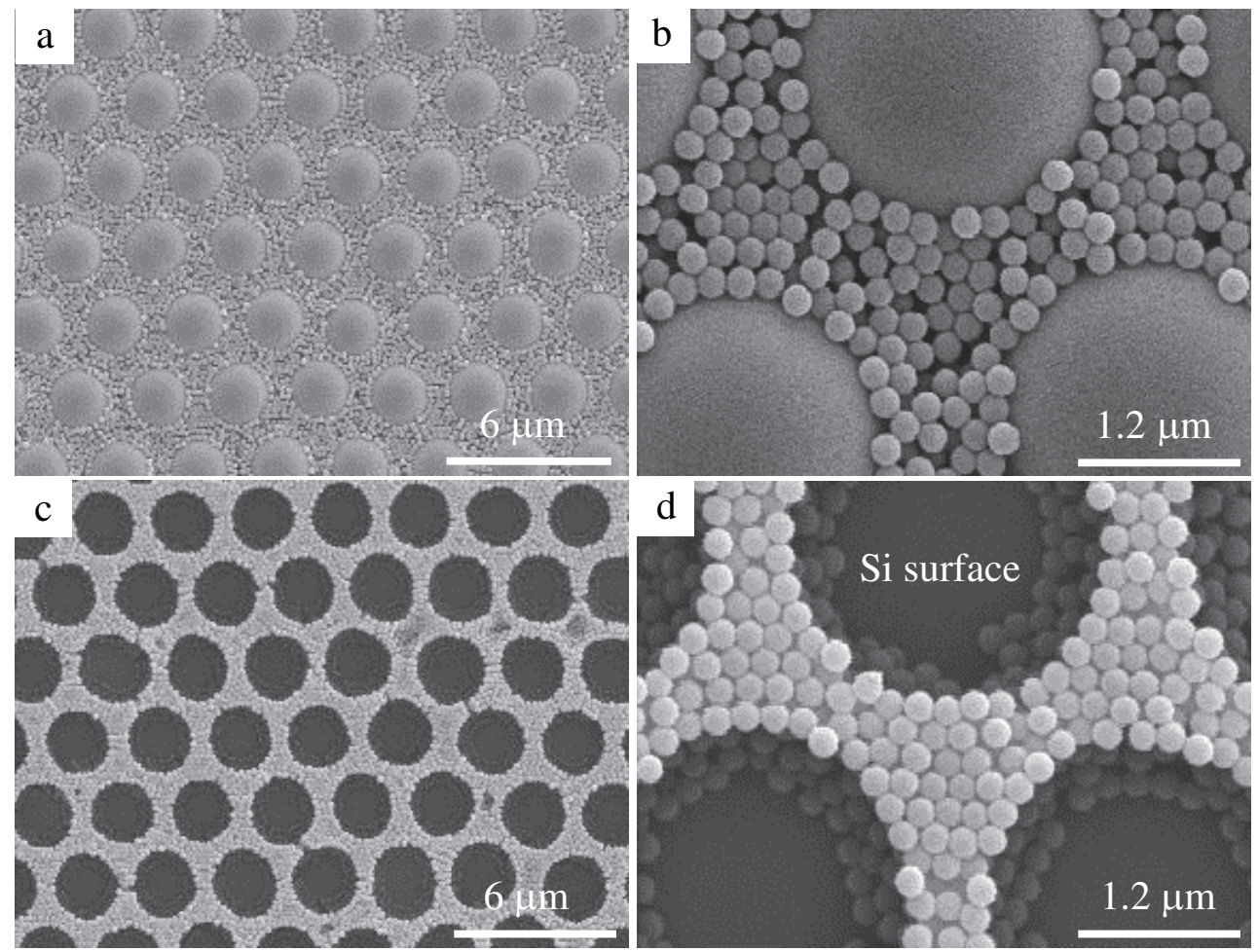

Fig. 7. SEM images of $(a, b)$ binary colloidal crystals and $(c, d)$ PS honeycomb mask after removing silica spheres by immersion in $10 \mathrm{wt} \% \mathrm{HF}$. The diameters of the large silica and small PS spheres were $3 \mu \mathrm{m}$ and $200 \mathrm{~nm}$, respectively. (a, c) Low-magnification view and (b, d) high-magnification view.

In addition, from a high-magnification AFM image of the same specimen, it was confirmed that the isolated circular $\mathrm{Pt}-\mathrm{Pd}$ thin films were composed of clusters of $\mathrm{Pt}-\mathrm{Pd}$ nanoparticles with a size range of $5-15 \mathrm{~nm}$, as shown in Fig. 9(a) (Asoh et al, 2009). Ion sputtering, which is generally used for coating nonconducting materials with a metal layer for SEM observations, was used for depositing $\mathrm{Pt}-\mathrm{Pd}$ in order to form a smoothly shaped metal thin film and to prevent the formation of a granular coating.

On the other hand, from the cross-section analysis of the AFM image of the deposited Au layer, the layer thickness was estimated to be $10-25 \mathrm{~nm}$ for a sputtering time of $3 \mathrm{~min}$, as shown in Fig. 8(d). The isolated Au circular thin films were also composed of clusters of $\mathrm{Au}$ nanoparticles with a size range of $10-30 \mathrm{~nm}$, as shown in Fig. 9(b). As compared to the isolated circular $\mathrm{Pt}-\mathrm{Pd}$ thin films, the Au nanoparticles in the isolated circular Au thin films varied considerably in size, and the surface of the deposit was markedly uneven with granular particles. 
a)

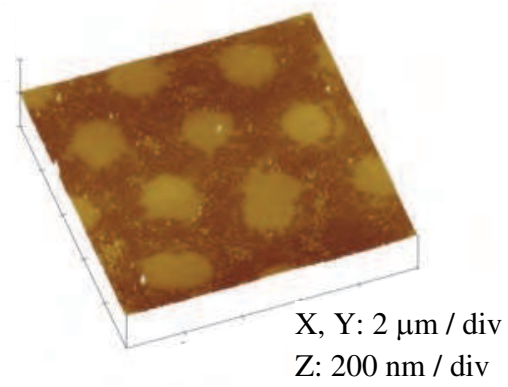

c)

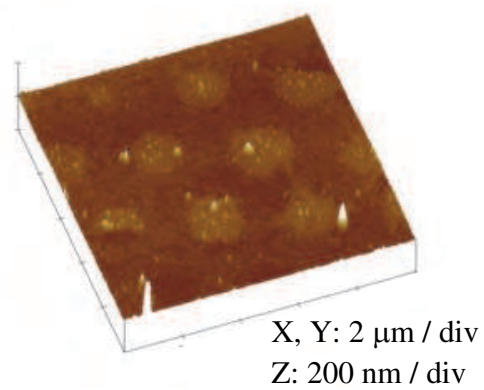

b)

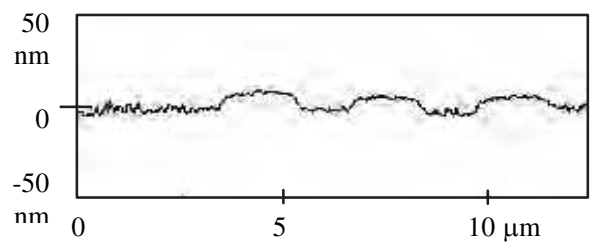

d)

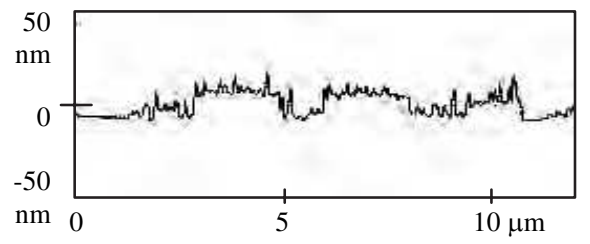

Fig. 8. AFM tapping-mode images of silicon surface after ion sputtering for $(a, b) 5 \mathrm{~min}$ using $\mathrm{Pt}-\mathrm{Pd}$ and (c, d) 3 min using Au. (b, d) Typical line scan images of cross-section of each specimen.

a)

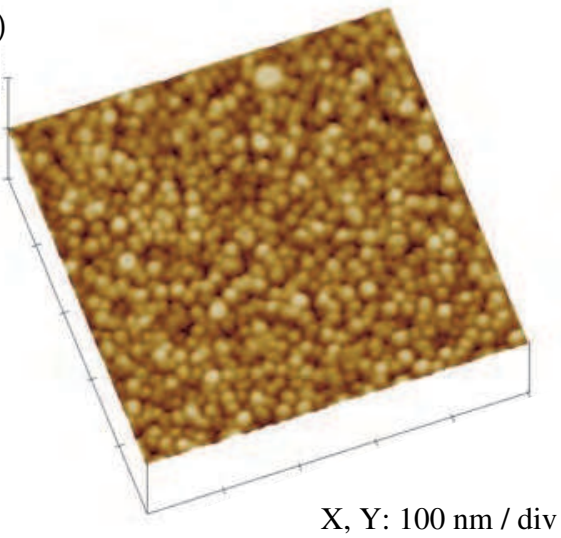

b)

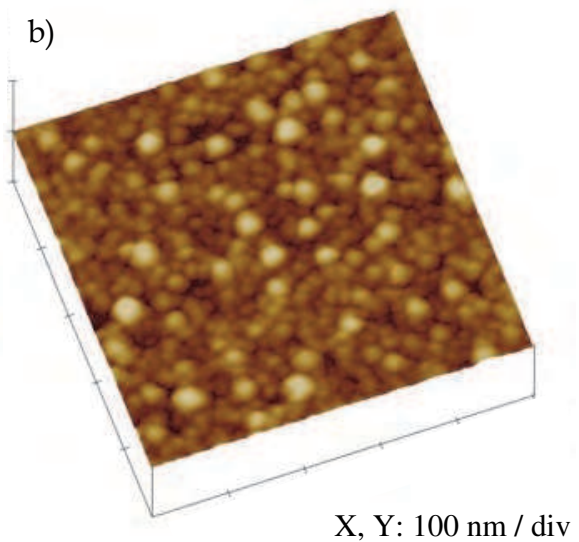

Fig. 9. High-magnification AFM images of (a) Pt - Pd and (b) Au films sputtered on Si substrate. Scan area was $500 \mathrm{~nm}^{2}$. 

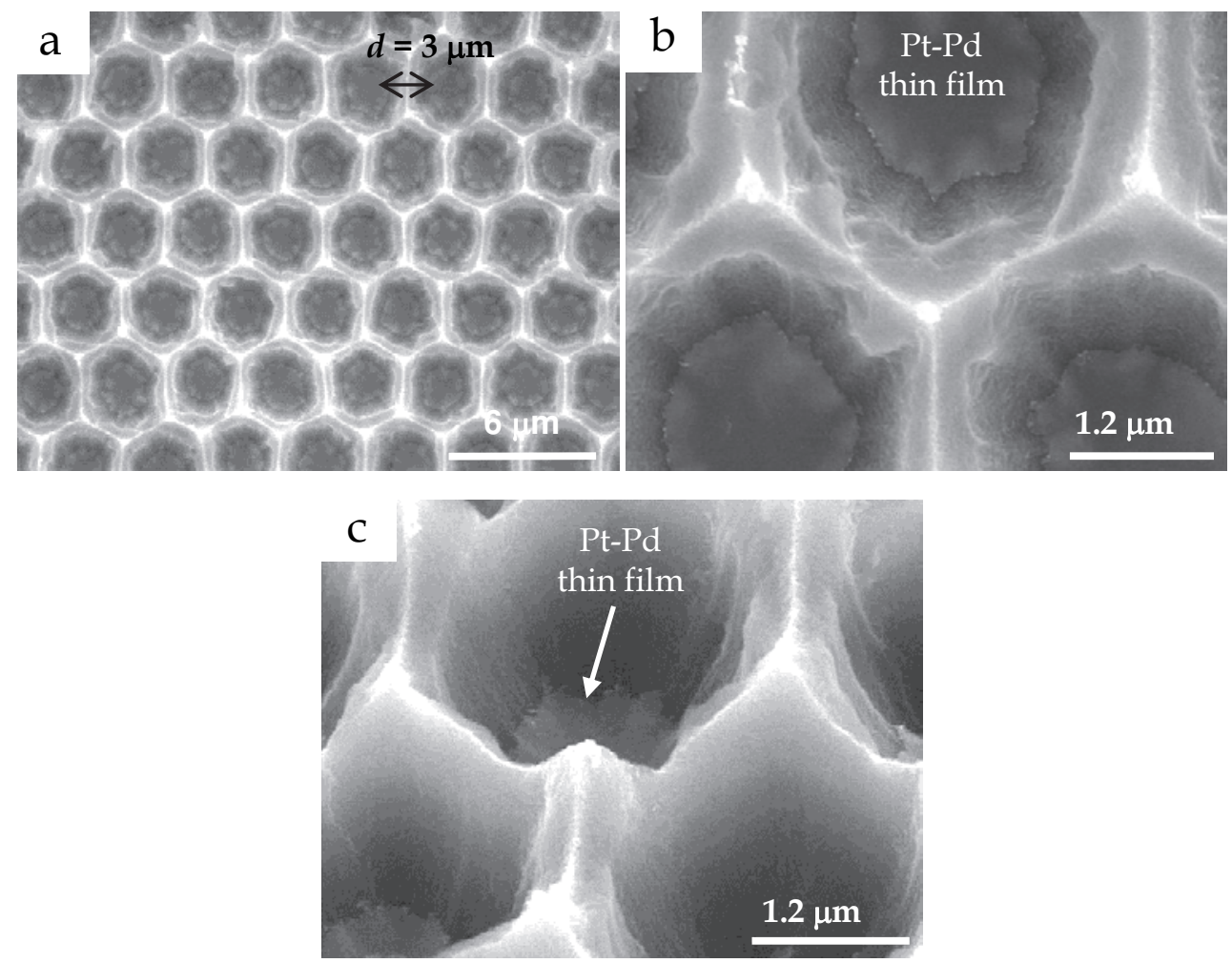

Fig. 10. (a) SEM image of macroporous silicon formed by metal-assisted chemical etching, (b) high-magnification view, and (c) tilted (45). Chemical etching was conducted in 5 mol $\mathrm{dm}^{-3} \mathrm{HF} / 1 \mathrm{~mol} \mathrm{dm}^{-3} \mathrm{H}_{2} \mathrm{O}_{2}$ for 3 min using a Pt-Pd catalyst.

By using circular metal thin films as a catalyst instead of metal nanoparticles, the formation of silicon microwells with micrometer-scale openings was also achieved by metal-assisted chemical etching. The etching conditions were the same as those using Ag nanoparticles as a catalyst (Fig. 2). During chemical etching, the central part of the silicon substrate surrounded by the honeycomb mask gradually sagged downward. Figures 10a-c show plane-view and tilted-view SEM images of the silicon surface etched using the patterned PtPd catalyst (Asoh et al, 2008a).

From the tilted view shown in Fig. 10c, it was confirmed that the pores were conical. The diameter of the opening of each silicon microwell was approximately $3 \mu \mathrm{m}$ due to the chemical dissolution of the horizontal plane. The depth of each silicon microwell was estimated to be approximately $2 \mu \mathrm{m}$. The crest and side walls of the silicon microwells were extremely smooth. In addition, the most noteworthy point is that the circular Pt-Pd thin films used as the catalyst remained at the bottom of each well. The SEM images shown in Figs. 10b and 10c revealed that the residual detected as bright contrast was the Pt-Pd catalyst. 

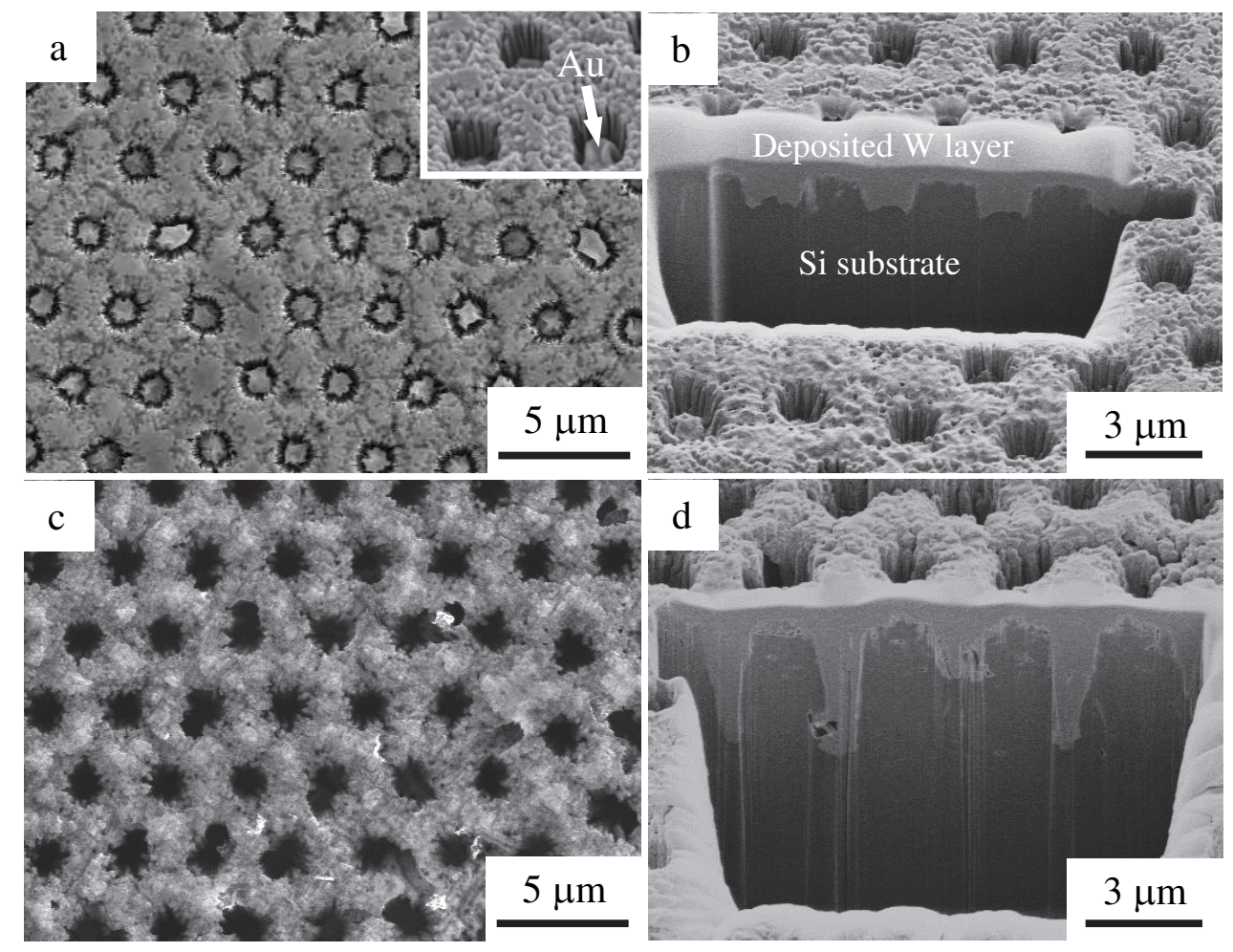

Fig. 11. SEM images of Au-coated silicon after chemical etching in $\mathrm{HF} / \mathrm{H}_{2} \mathrm{O}_{2}$ for $(\mathrm{a}, \mathrm{b}) 1 \mathrm{~min}$ and (c, d) 5min. (a, c) Top view and (b, d) cross-sectional view of silicon prepared by FIB. The periodicity of the PS honeycomb mask was $3 \mu \mathrm{m}$.

\subsection{Effect of noble metal catalyst species on morphology of macroporous silicon formed by metal-assisted chemical etching}

To examine the effect of the catalyst species on the morphology of the etched silicon structure, chemical etching was also carried out using patterned Au thin films. Figure 11 shows the surfaces and cross-sectional images of silicon after chemical etching using the patterned Au thin films (Asoh et al, 2009). Before carrying out FIB processing to observe the cross section of the pores, tungsten was deposited on surface of the specimens to prevent damage to the etched silicon surface by gallium ion beam. Although metal-assisted chemical etching was carried out using $\mathrm{Au}$ catalyst under the same etching conditions indicated in Fig. 10, the morphology of the resultant porous structure was significantly different from that of the silicon macropores formed using Pt-Pd catalyst.

When the etching time was equal to $1 \mathrm{~min}$, the localized dissolution of silicon was observed only on the silicon surface covered with Au thin films [Figs. 11(a) and 11(b)]. After carrying out metal-assisted chemical etching for $5 \mathrm{~min}$, the pore depth increased up to $5 \mu \mathrm{m}$. The etching rate was estimated to be approximately $1 \mu \mathrm{m} \mathrm{min}-1$. One of the 
notable features of metal-assisted chemical etching using Au catalyst is the suppression of pore widening at the outermost surface of silicon. The diameter of the pores hardly increased during chemical etching. The dissolution of silicon was accelerated locally at the silicon/metal interface in the direction of the pore depth, resulting in the formation of macropores with a relatively high aspect ratio.
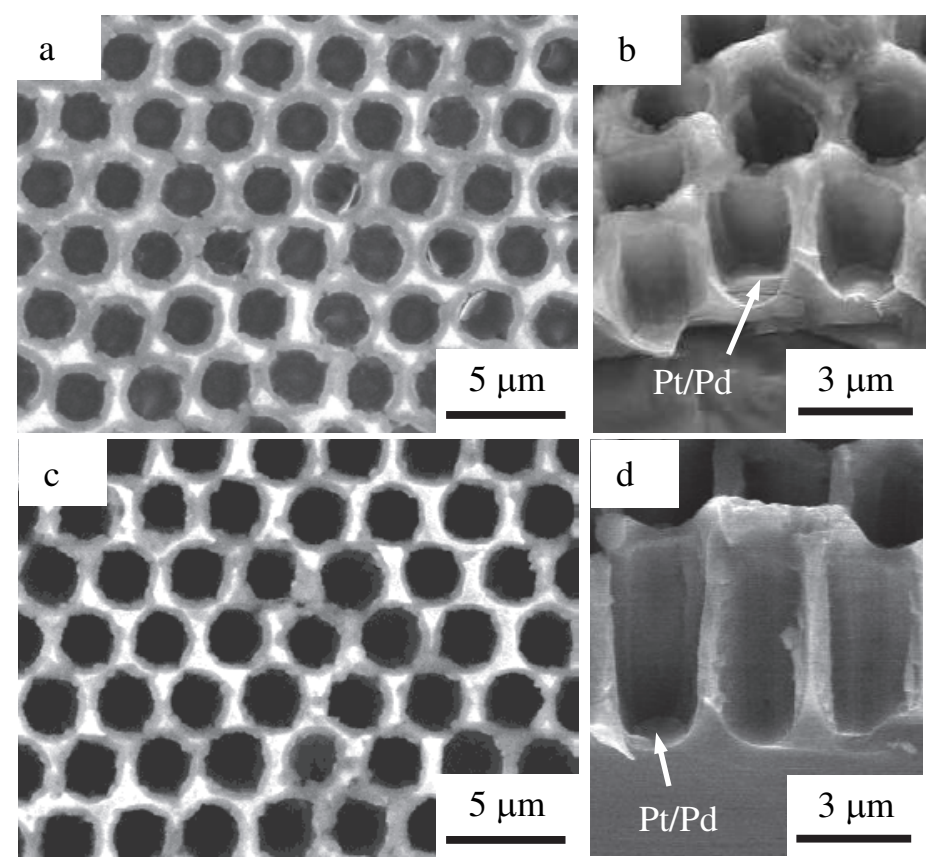

Fig. 12. SEM images of Pt-Pd-coated silicon after chemical etching in $\mathrm{HF} / \mathrm{H}_{2} \mathrm{O}_{2}$ for $(\mathrm{a}, \mathrm{b}) \mathrm{I}$ min and (c, d) 2 min. $(a, c)$ Top view and $(b, d)$ cross-sectional view. Chemical etching was conducted after removing PS honeycomb mask.

The following factors are considered as the reasons behind the suppression of pore widening. (I) As discussed previously, the isolated Au circular thin films are composed of clusters of $\mathrm{Au}$ nanoparticles with a relatively large size. Thus, the configuration of metal catalysts affects the morphology of pores due to the catalytic action of the catalysts. (II) The diffusion area of $\mathrm{h}^{+}$ during pore formation in the presence of $\mathrm{Au}$ catalyst is narrower than that of $\mathrm{Pt}-\mathrm{Pd}$ catalyst. The injection/diffusion behaviour of $\mathrm{h}^{+}$is assumed to be affected by a Schottky barrier formed at the silicon/metal interface and the work function of each noble metal.

Figure 12 shows the SEM images of Pt-Pd-coated silicon after chemical etching in $\mathrm{HF} / \mathrm{H}_{2} \mathrm{O}_{2}$ (Asoh et al, 2009). In this case, chemical etching was carried out after removing the PS honeycomb mask. A comparison with Fig. 10 showed that despite employing the same etching conditions, the preferential dissolution of silicon in this case remarkably proceeded in the direction of pore depth. It was also apparent that pore widening at the 
silicon surface was effectively suppressed. After metal-assisted chemical etching for 2 min, the pore depth increased up to $7 \mu \mathrm{m}$. The etching rate, which was estimated to be approximately $3.5 \mu \mathrm{m} \mathrm{min}-1$, was $\sim 2$ times faster than that of etching carried out using the PS mask and Pt-Pd catalyst, as shown in Fig. 10, and $\sim 3.5$ times faster than that of $\mathrm{Au}$ catalyst, as shown in Fig. 11. When metal catalysts were located in isolation on the silicon substrate and the PS honeycomb mask was not used, the diffusion of hydrogen produced by the reduction of protons and the dissolution of silicon probably proceeded effectively. As a result, straight macropores were formed within a relatively short etching time, and excessive pore widening at the outermost surface of macroporous silicon was prevented.

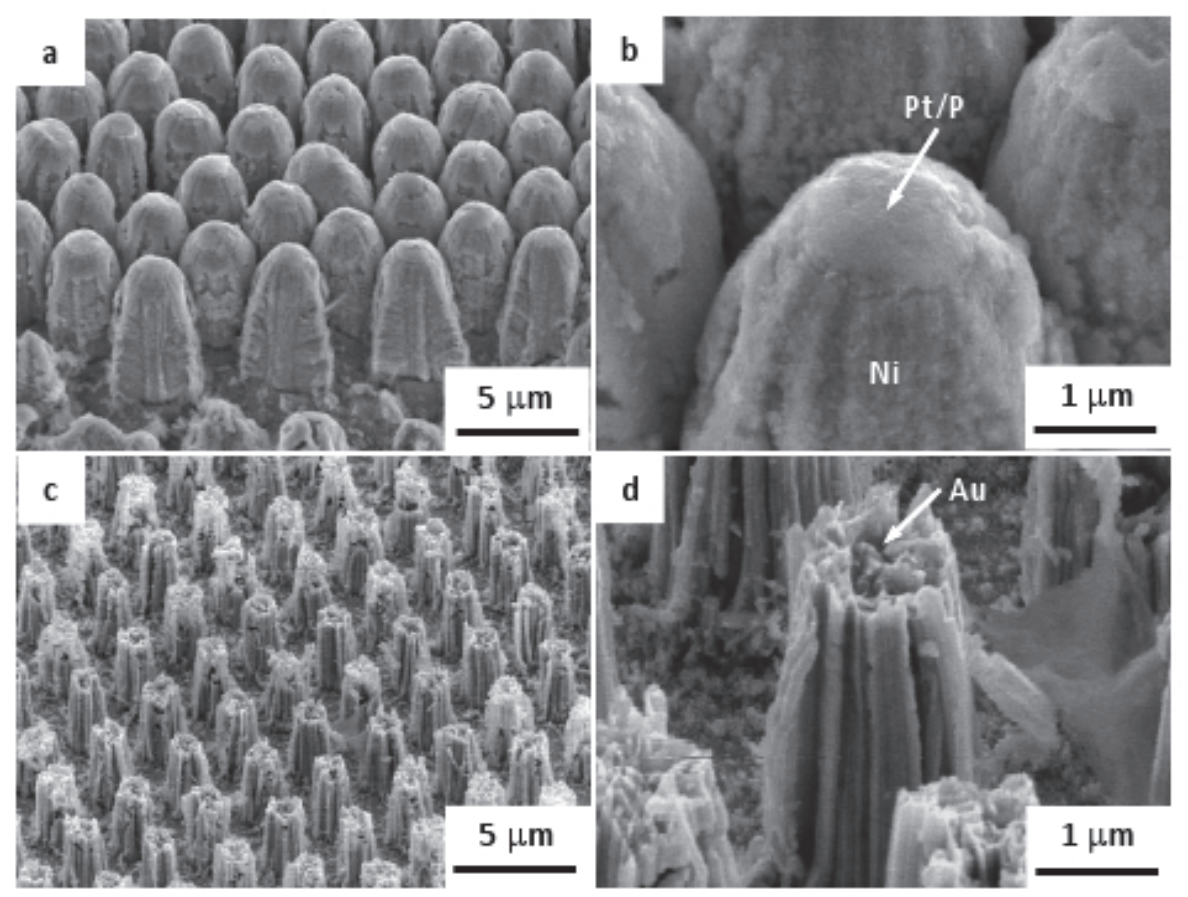

Fig. 13. SEM images of nickel replica of etched silicon. (a, b) Pt-Pd-coated silicon was etched for $2 \mathrm{~min}$. (c, d) Au-coated silicon was etched for $3 \mathrm{~min}$. (b, d) High-magnification view of each specimen. SEM observation was conducted from an angle of $45^{\circ}$ to the surface.

To evaluate the morphology of the porous structure in the direction of pore depth, a nickel replica was prepared by metal plating using obtained macroporous silicon as a template. From the SEM image of the obtained nickel replica shown in Fig. 13, it was confirmed that the height of nickel rods, that is, the depth of the pores was almost uniform in both specimens (Asoh et al, 2009). These images of the nickel replica were basically compatible with the SEM images of macroporous silicon. However, the shape of the side surface of the nickel rods was found to differ in the case of each specimen. In the case of Pt-Pd catalyst, the side surface of nickel rods, that is, the side walls of the silicon macropores were relatively smooth. It should be noted that the obtained nickel rods had Pt-Pd thin films at their tips. This result also revealed that metal-assisted chemical etching proceeded only in the Pt-Pd- 
coated area on the silicon surface. On the other hand, in the case of Au catalyst, a number of channels were observed on the side surface of the nickel rods. Such structure is thought to be reflected in the traces of Au nanoparticles divided from circular thin film. In other words, the outer surface of silicon macropores was composed of the cluster of nanopores with sizes in the range of 50-100 $\mathrm{nm}$. Suppression of pore widening during metal-assisted chemical etching using Au catalyst may be caused by the specific catalytic action of Au nanoparticles.
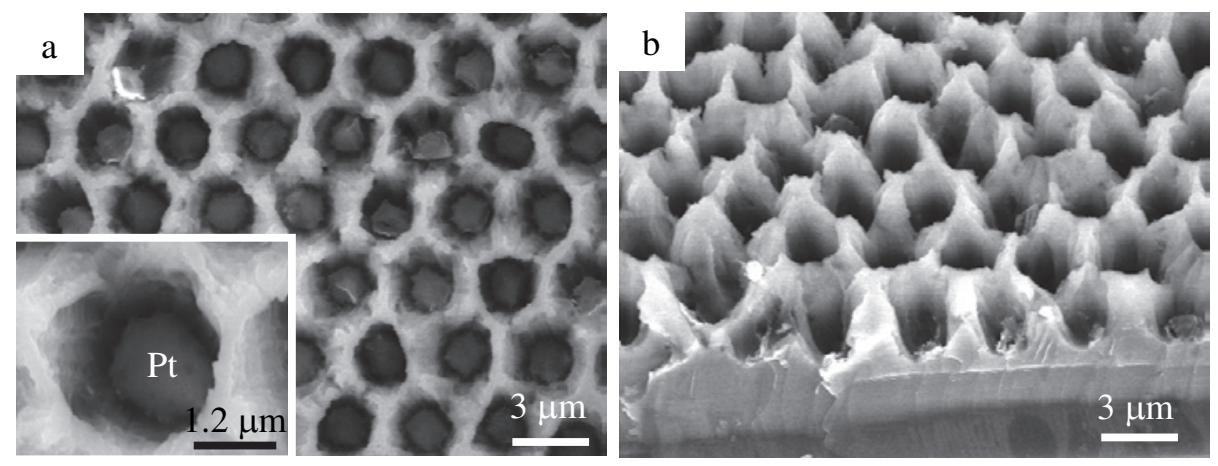

Fig. 14. SEM images of Pt-coated silicon after chemical etching in $\mathrm{HF} / \mathrm{H}_{2} \mathrm{O}_{2}$ for $1 \mathrm{~min}$. (a) Top view and (b) cross-sectional view. Chemical etching was conducted after removing PS honeycomb mask. Inset shows a high-magnification top view of the same specimen.

On the basis of the present method, ordered macropore arrays could be formed independent of noble metal catalyst species. Figure 14 shows the silicon macropore arrays formed by metal-assisted chemical etching using Pt single catalyst (Asoh et al, 2009). Metal-assisted chemical etching was carried out after removing the PS honeycomb mask. The etching behaviour when Pt catalyst was used was basically similar that in the case of Pt-Pd catalyst. From the tilted view of the specimen shown in Fig. 14(b), the pore depth after metal-assisted chemical etching for $1 \mathrm{~min}$ was estimated to be approximately $3 \mu \mathrm{m}$. A detailed study is under way for the clarification of the effect of Pd single catalyst.

The relationship between the pore depth and the etching time is summarized in Fig. 15 (Asoh et al, 2009). In addition to the results for the metal-assisted chemical etching carried out using the PS mask, the results obtained without using the PS mask are also plotted for each metal species. In the present study, etching rate increases in the following order: Au < $\mathrm{Pt} \leq \mathrm{Pt}-\mathrm{Pd}$. If the metal catalyst species are the same, the etching rate without using the mask is faster than that obtained using the mask. Further research on metal-assisted chemical etching using metal thin films as a catalyst would clarify the relationship between the mechanism for controlling the morphology of the resultant pattern and the etching conditions, such as the composition and concentration of an etchant, substrate parameters, resistivity, and doping density.

We described the differences in the catalytic action of Pt-Pd (or Pt) and $\mathrm{Au}$ catalysts on the morphology of etched silicon microstructures. In the case of $\mathrm{Pt}-\mathrm{Pd}$, although etching rate was faster than that of $\mathrm{Au}$, there was excessive pore widening at the outermost surface due to the chemical dissolution of the horizontal plane. On the other hand, straight pores with relatively small diameter were obtained by using Au catalyst under the same etching 
conditions. Thus, the dissolution of silicon by using Au thin films as a catalyst was locally accelerated at the silicon/metal interface in the direction of the pore depth. The morphology of the resultant porous structure was assumed to be affected by the difference in the shape of metal catalyst and the diffusion behaviour of injected positive holes at the silicon/metal interface.

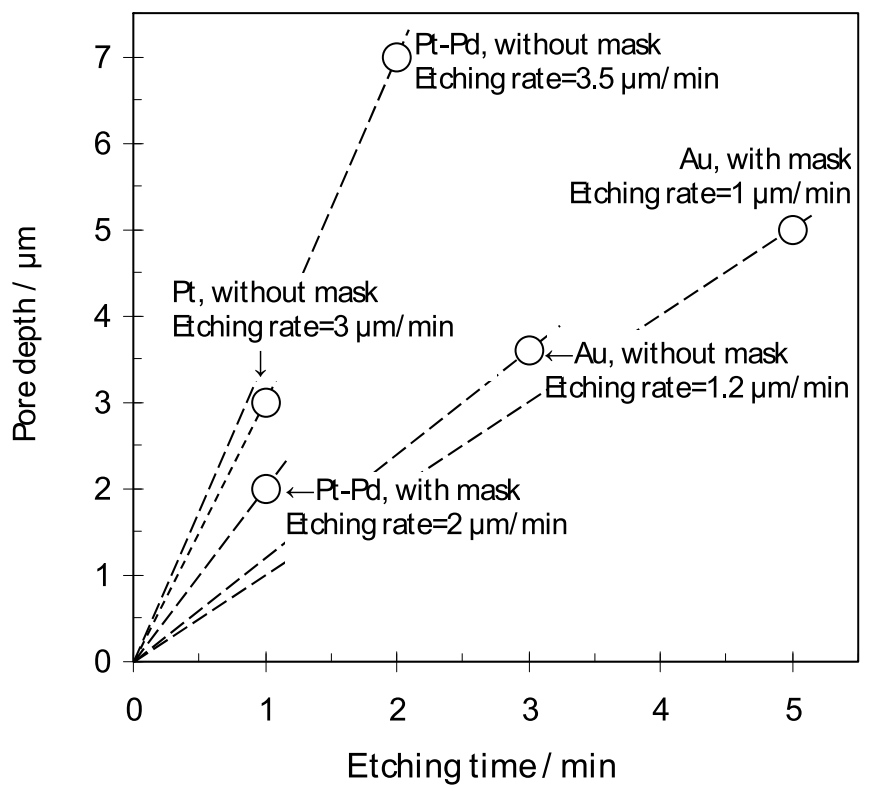

Fig. 15. Relationship between depth of pores formed by metal-assisted chemical etching using various noble metals and corresponding etching time.

\subsection{Fabrication of macroporous silicon with a high aspect ratio}

Figure 16 shows macroporous silicon with a high aspect ratio formed using circular Pt-Pd thin films as a catalyst. When metal-assisted chemical etching was conducted in HF with a high concentration of $10 \mathrm{~mol} \mathrm{dm}^{-3}$, the morphology of the resultant porous structure was significantly different from that of the silicon microwells formed in HF with a relatively low concentration of $5 \mathrm{~mol} \mathrm{dm}^{-3}$ (Ono et al, 2009). In the case of low-concentration HF, injected positive holes are expected to diffuse into silicon bulk and oxidize silicon at locations away from the metal-coated silicon surface. On the other hand, in the case of high-concentration $\mathrm{HF}$, the diffusion of positive holes is thought to be suppressed. One of the notable features of the obtained porous structure is that the diameter of each pore was hardly increased during chemical etching. Namely, the dissolution of silicon oxide is accelerated locally at the silicon/metal interface in the direction of the pore depth, resulting in the formation of macroporous silicon with a high aspect ratio. Further research on metal-assisted chemical etching using metal thin films as a catalyst would clarify the relationship between the mechanism for controlling the morphology of the resultant pattern and the etching conditions, such as the composition and concentration of etchant, substrate parameters, resistivity, and doping density. 


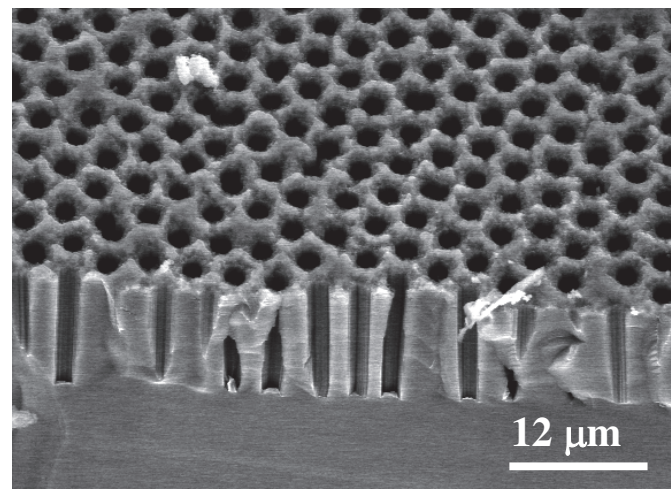

Fig. 16. Cross-sectional SEM image of macroporous silicon formed by metal-assisted chemical etching. Chemical etching was conducted in $10 \mathrm{~mol} \mathrm{dm}^{-3} \mathrm{HF} / 1 \mathrm{~mol} \mathrm{dm}^{-3} \mathrm{H}_{2} \mathrm{O}_{2}$ for 2 min using a Pt-Pd catalyst.

\section{Periodic GaAs convex and hole arrays by metal-assisted chemical etching}

\subsection{Periodic micro GaAs convex arrays}

GaAs nanostructures have been studied extensively, particularly from the viewpoint of their application to optoelectronic devices. For instance, the characteristic photoluminescence of GaAs porous structures that are produced by the polarization of the substrate in $\mathrm{HCl}$ solution has been reported previously (Schmuki et al, 1996). The design and fabrication of periodically ordered GaAs structures will lead to the development of new functional materials and devices in the future.

Studies have focused on the metal-assisted chemical etching of GaAs, and its effectiveness has been demonstrated (Yasukawa et al, 2008a, 2008b, 2008c, 2009). We fabricated GaAs convex arrays through electroless plating of $\mathrm{Ag}$ and $\mathrm{Pd}$ as metal catalysts and templating based on self-organized polystyrene (PS) spheres; however, convex structures with superior aspect ratios have not been obtained (Yasukawa et al, 2008a, 2008b, 2009). Herein, we describe the fabrication of GaAs convex and hole arrays using an ion-sputtered Pt-Pd catalyst to improve the aspect ratio of the etching structure. Pt-Pd was used because it markedly accelerates the etching rate of $\mathrm{p}-\mathrm{Si}$, and etching structures with a high aspect ratio were obtained (Asoh et al, 2009).

To fabricate convex arrays, Pt-Pd was selectively sputtered onto the substrate in the spaces among PS spheres through the PS mask so that a Pt-Pd honeycomb pattern was formed on GaAs. After Pt-Pd-metal-assisted chemical etching for $20 \mathrm{~s}$ in a mixed solution of $5 \mathrm{~mol} \mathrm{dm}^{-3}$ $\mathrm{HF}$ and $1 \mathrm{~mol} \mathrm{dm}^{-3} \mathrm{H}_{2} \mathrm{O}_{2}$, ordered $\mathrm{GaAs}$ convex arrays were thus obtained as shown in Figs. 17(a) and 17(b) (Yasukawa et al, 2010). The etching depth was approximately $330 \mathrm{~nm}$. GaAs was chemically dissolved using the etchant described above without the use of metal catalysts, resulting in two-dimensional striped etching patterns, i.e., anisotropic etching took place (Yasukawa et al, 2008b, 2009). The anisotropic etching in the present $\mathrm{HF} / \mathrm{H}_{2} \mathrm{O}_{2}$ etchant was due to preferential etching of GaAs in the <010> crystallographic direction at an etching rate of $\sim 0.2 \mathrm{~nm} \mathrm{~s}^{-1}$. If the preferential etching direction is [010] or [010], then [001] or [001] is assumed to be the less preferential etching direction and vice versa. 
The calculated etching rate of the convex arrays in the direction perpendicular to the substrate, [100], was $\sim 16.7 \mathrm{~nm} \mathrm{~s}^{-1}$. The etching rate using Pt-Pd was approximately two orders of magnitude higher than that in chemical dissolution. The metal-assisted chemical etching rates using $\mathrm{Ag}, \mathrm{Pd}$, and $\mathrm{Au}$ as catalysts were $\sim 0.6, \sim 4.7$, and $\sim 8.1 \mathrm{~nm} \mathrm{~s}^{-1}$, respectively (Yasukawa et al, 2008a, 2008b, 2008c, 2009); therefore, Pt-Pd-metal-assisted chemical etching was much faster and the aspect ratio of the resulting structure was improved. The difference between the work functions of each catalytic metal species could be one of the reasons for the difference between the metal-assisted chemical etching rates of $\mathrm{Ag}, \mathrm{Pd}, \mathrm{Au}$, and $\mathrm{Pt}-\mathrm{Pd}$. In previous studies, empirically determined work functions were reported to be $4.26 \mathrm{eV}$ for $\mathrm{Ag}$ (Dweydari and Mee, 1975), $5.12 \mathrm{eV}$ for Au (Nieuwenhuys et al, 1974), $5.65 \mathrm{eV}$ for Pt (Eastman, 1970), and $5.12 \mathrm{eV}$ for Pd (Nieuwenhuys et al, 1974). In the metal-assisted chemical etching of a $\mathrm{Si}$ substrate, the fast etching rate originates from the higher work function, i.e., the relative ease of $\mathrm{h}^{+}$ejection (Asoh et al, 2009); the metal-assisted chemical etching rates of GaAs were highly consistent with this tendency. Therefore, it is reasonable for the Pt-Pd-assisted etching rate to be higher than those using other catalysts.
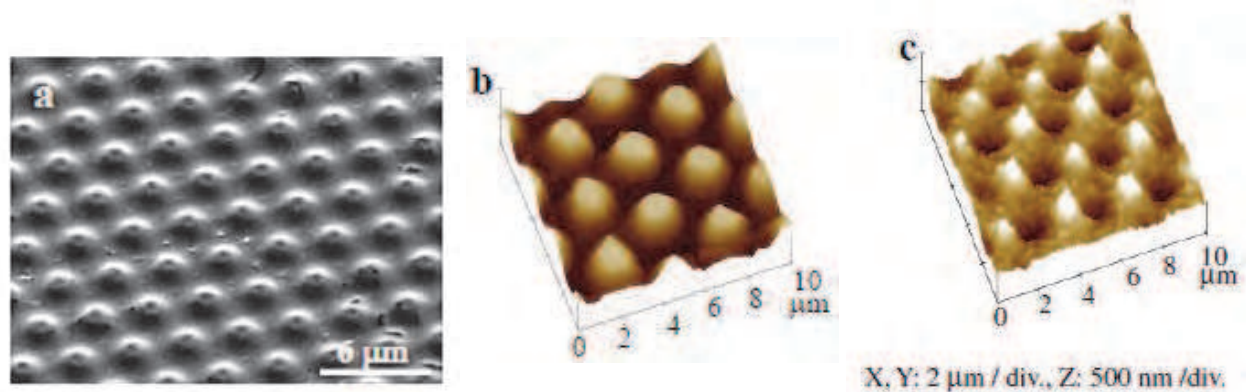

$\mathrm{X}, \mathrm{Y}: 2 \mu \mathrm{m} / \mathrm{div}, \mathrm{Z}: 500 \mathrm{~mm} / \mathrm{div}$.

Fig. 17. GaAs convex structures obtained by Pt-Pd-metal-assisted chemical etching for $20 \mathrm{~s}$ in a solution of $5 \mathrm{~mol} \mathrm{dm}^{-3} \mathrm{HF}$ and $1 \mathrm{~mol} \mathrm{dm}^{-3} \mathrm{H}_{2} \mathrm{O}_{2}$. (a) SEM image at 45 (to the surface and (b) AFM image. (c) AFM image of convex arrays formed by etching for $60 \mathrm{~s}$.

Figure 17(c) shows convex arrays fabricated by etching for $60 \mathrm{~s}$ with a depth of $\sim 430 \mathrm{~nm}$. The etching rate was $\sim 7.2 \mathrm{~nm} \mathrm{~s}^{-1}$. The etching rate calculated from the structure was lower than that in the case of etching for $20 \mathrm{~s}$. The rate of metal-assisted chemical etching is determined by the species of the substrate and the catalytic metal species, thereby the etching rate is constant as long as the same substrate and catalytic metal are used. The decrease in the etching rate with increasing etching time [Fig. 17(c)] was thus a consequence of the chemical dissolution of the convex structure itself (Yasukawa et al, 2010).

\subsection{Periodic micro GaAs hole arrays}

GaAs hole arrays [Figs. 18(a) and 18(b)] were fabricated by metal-assisted chemical etching for $60 \mathrm{~s}$ using the PS-honeycomb structural mask in the same etching solution as above (Yasukawa et al, 2010). Pt-Pd was deposited selectively in traces of $\mathrm{SiO}_{2}$ spheres to form island-like patterns. GaAs was then etched to form hole arrays. The part of the substrate where Pt-Pd had not been deposited did not undergo metal-assisted chemical etching; however, striped etching patterns resulting from the anisotropic etching of the substrate surface were observed. Because Pt-Pd-metal-assisted chemical etching was performed after 
the removal of the mask, chemical dissolution occurred at the surface. The shapes of holes were approximately circular but somewhat elongated in the lateral direction in the images of samples with an average etch depth of $\sim 670 \mathrm{~nm}$. The metal-assisted chemical etching proceeded perpendicular to the substrate owing to $h^{+}$being injected from the catalytic metal into GaAs. The diffusion of $\mathrm{h}^{+}$to the hole wall away from the catalytic metal/substrate interface occurs in all crystallographic directions in the substrate. However, anisotropic chemical dissolution depends on the substrate crystallography; therefore, the holes were elongated in the lateral direction (preferential etching direction).

Anisotropic etching is the most characteristic in GaAs because the crystallography of the underlying substrate strongly affects the resultant etching morphology. Such etching cannot be observed in the metal-assisted chemical etching of $\mathrm{Si}$; therefore, different morphologies were observed between $\mathrm{GaAs}$ and $\mathrm{Si}$ fabricated by metal-assisted chemical etching even when the same metal catalyst was used.
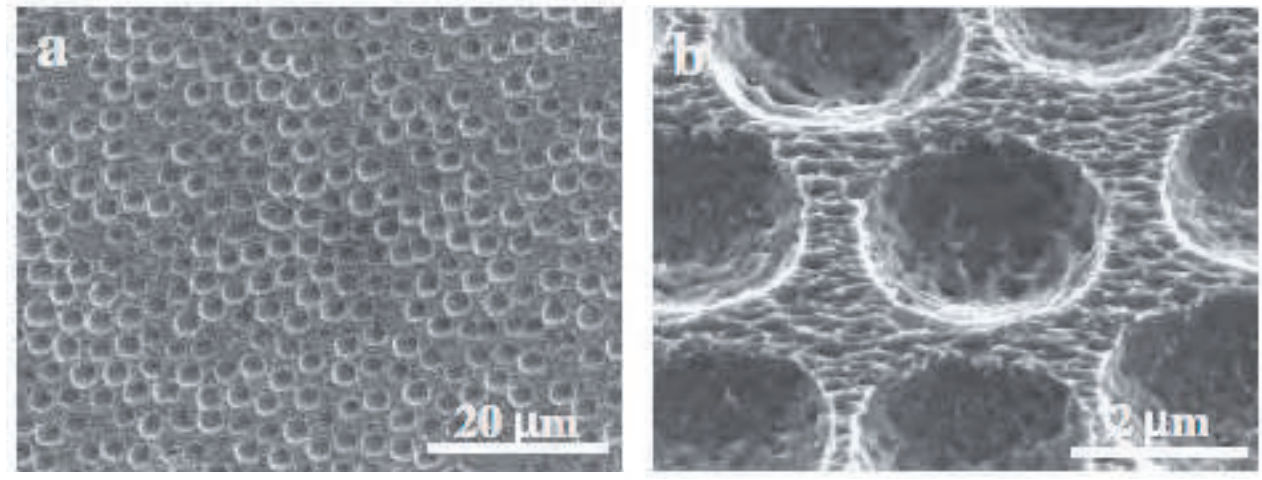

Fig. 18. SEM images of GaAs hole arrays fabricated by Pt-Pd-metal-assisted chemical etching for $60 \mathrm{~s}$ in a solution of $5 \mathrm{~mol} \mathrm{dm}^{-3} \mathrm{HF}$ and $1 \mathrm{~mol} \mathrm{dm}^{-3} \mathrm{H}_{2} \mathrm{O}_{2}$ observed from (a) top and (b) at $45^{\circ}$ to the surface.

\section{Ordered hexagonal array of crystalline Au nanodots on Silicon}

Metal nanoparticles and nanodots have been a focus of intense research due to their novel physical properties in reference to their bulk counterparts (Daniel and Astruc, 2004). In addition, collective properties can arise due to the interactions of the individual nanoparticles in ordered arrays (Motte et al, 1997; Wang et al, 2007). This is why the control of individual dot properties (with controllable size and shape) and their relative arrangements (density, pattern shape) are crucial. Nanodots patterned in ordered arrays, especially gold nanodots, have been proposed for a wide range of applications, such as magnetic data storage, optoelectronic devices, biosensors and catalysts for the growth of aligned one-dimensional nanostructures.

In the past few years many methods have been developed for nanodot array patterning, such as focused ion beam or e-beam lithography, molecular beam epitaxy (MBE), chemical vapor deposition (CVD), selfassembly and template-based methods by using porous anodic alumina membranes as evaporation masks. However, most fabrication processes mentioned 
above are not satisfactory due to some drawbacks, such as low throughput, high cost of equipment and low uniformity of the shapes and sizes of dots.

We reported previously that metal patterns of two different types, that is, network-like honeycomb and isolated-island patterns with ordered periodicities (200 nm - $3 \mu \mathrm{m})$, were formed on an $\mathrm{Si}(100)$ substrate by a combination of colloidal crystal templating, hydrophobic treatment and subsequent siteselective electrodeless deposition (Asoh et al, 2007a, 2007c). Based on this strategy, it is possible to control the configuration of metal dot arrays by changing the mask structure for metal deposition.

We focus in particular on the controllability of the morphology and crystallinity of $\mathrm{Au}$ nanodots and try to control the heteroepitaxial growth of Au dots on Si surfaces by high temperature annealing above the eutectic temperature in an $\mathrm{Au}-\mathrm{Si}$ system.
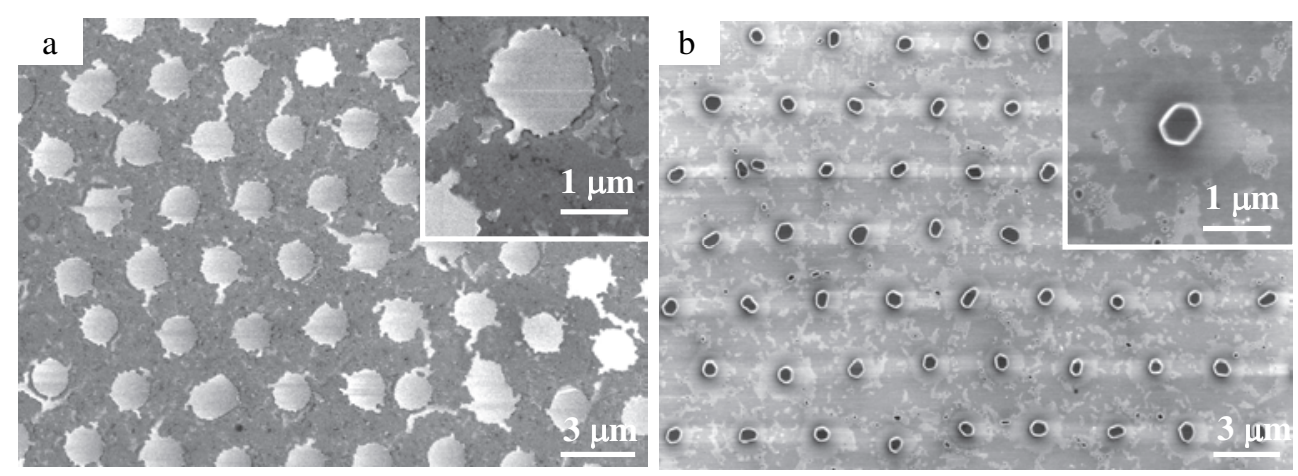

Fig. 19. (a) Au thin films pattern formed by sputter coating through PS honeycomb mask and removal of PS honeycomb mask. (b) Hexagonally-arranged Au nanodot arrays formed by annealing in Ar ambient.

In the present study, the PS honeycomb structure was applied as a mask for metal deposition. When sputtering was conducted through the PS honeycomb mask, isolated circular Au thin films with approximately $1.5 \mu \mathrm{m}$ diameter and a density of $\sim 1 \times 10^{7} \mathrm{~cm}^{-2}$ were deposited in the interspaces of the PS mask as shown in Fig. 19(a) (Sakamoto et al 2008). Each thin film consisted of polycrystalline granular Au particles with $20-40 \mathrm{~nm}$ grains. After the deposition of the $\mathrm{Au}$ thin films on the $\mathrm{Si}(111)$ substrate, the specimens were annealed under an argon atmosphere to control the morphology and the crystallinity of the deposited Au. Figure 19(b) shows an SEM image of the Au nanodot arrays after heat treatment for $1 \mathrm{~h}$ at $600{ }^{\circ} \mathrm{C}$ above the eutectic temperature $\left(363{ }^{\circ} \mathrm{C}\right)$ in an $\mathrm{Au}-\mathrm{Si}$ system. Au thin films composed of granular nanoparticles were self-assembled into spherical $\mathrm{Au}$ nanoislands by thermo migration. The diameter of each $\mathrm{Au}$ dot was approximately $650 \mathrm{~nm}$ (inset). Chemical analyses by EDX show that the heat treatment under argon does not change the chemical composition of the nanodots. The density of the nanodots is also still unchanged.

From the tilted view, it was confirmed that the shape of the Au nanodots was a truncated hexagonal dipyramid with defined facets (Fig. 20(a)) (Sakamoto et al 2008). The height of the thermally crystallized Au dot was approximately $260 \mathrm{~nm}$. To identify the crystal structure of the Au dot, EBSD analysis was performed. In fact, electron backscatter diffraction (EBSD) is a 
technique which allows crystallographic information to be obtained from samples in the scanning electron microscope (SEM). In EBSD a stationary electron beam strikes a tilted crystalline sample and the diffracted electrons form a pattern on a fluorescent screen. This pattern is characteristic of the crystal structure and orientation of the sample region from which it was generated. The diffraction pattern can be used to measure the crystal orientation, measure grain boundary misorientations, discriminate between different materials and provide information about local crystalline perfection. When the beam is scanned in a grid across a polycrystalline sample and the crystal orientation measured at each point, the resulting map will reveal the constituent grain morphology, orientations and boundaries. This data can also be used to show the preferred crystal orientations present in the material.

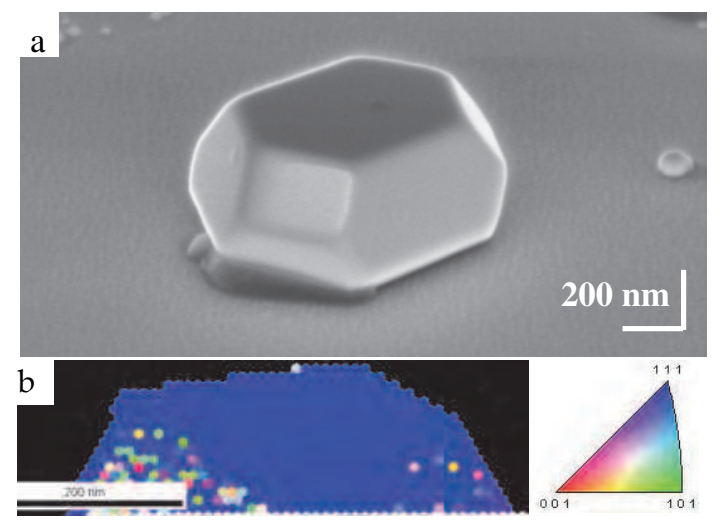

Fig. 20. (a) Tilted $\left(60^{\circ}\right)$ SEM image of Au nanodots. (b) Color mapping (colour online) of crystal orientation of Au nanodots by EBSD analysis (the area analyzed by EBSD is marked by the rectangle in (a)). A pattern quality map is plotted in the background and data is cleaned. (Sakamoto et al 2008)

Figure 20(b) shows EBSD mapping images of a side view of one dot. From EBSD analysis, it was ascertained that Au nanodots formed on $\mathrm{Si}(111)$ were almost single crystals with a (111) crystal face. We do not observe another crystal orientation. The shape difference observed in Fig. 19(b) can be related to the fact that all the nanodots under this heat treatment condition do not possess the perfect equilibrium structure (truncated hexagonal dipyramid with defined facets) (Shi and Stampfl, 2008). This specific growth of Au dots was assumed to be caused by the crystal orientation of the underlying $\mathrm{Au} / \mathrm{Si}$ intermixed layer, that is, the $\mathrm{Au}$ silicide interfacial layer. Several studies have been carried out on interfacial phenomena between metals $(\mathrm{Au})$ and semiconductors $(\mathrm{Si})$ due to its importance in electronic devices and interconnects, and it is well known that Au silicide is formed due to diffusion of Si through the Au film during the annealing process (Ressel et al, 2003; Flammini et al, 2004; Negishi et al 2006). In addition, epitaxial growth of truncated hexagonal dipyramidal Au nanodots on the Au silicide phase of $\mathrm{Au}_{7} \mathrm{Si}$ has been reported (Wu et al, 2003). According to their report, metallic $\mathrm{Au}$ was grown epitaxially on the $\mathrm{Au}_{7} \mathrm{Si}(111)$ because the lattice spacing matches well, that is, the lattice mismatch is $3.4 \%$ with two unit cells of Au matching a single unit cell of $\mathrm{Au}_{7} \mathrm{Si}$ in the (111) orientation. In the present study, it is inferred from the specific morphology of the Au nanodot that the epitaxial growth of Au nanodots could be controlled by the crystal orientation of the underlying Au silicide as well as $\mathrm{Si}(111)$. 


\section{Conclusion}

The process presented in this paper is suitable for the large-scale production of ordered silicon macropores containing noble metal thin films, which cannot be fabricated by conventional lithographic techniques, because this patterning process involves colloidal crystal templating based on a relatively easy chemical treatment. On the basis of the present process, different types of noble metal films can also be embedded within a silicon substrate. Further research on the preparation of three-dimensional silicon microstructures by metalassisted chemical etching would help us to determine their potential applications in optical devices, chemical sensors, and silicon-based biofunctional devices.

\section{Acknowledgments}

Part of this work was financially supported by a Grant-in-Aid for Scientific Research from the Japan Society for the Promotion of Science and the Light Metal Education Foundation of Japan. Thanks are also due to a grant of Strategic Research Foundation Grant-aided Project for Private Universities from Ministry of Education, Culture, Sport, Science, and Technology, Japan (MEXT).

\section{References}

Asoh, H.; Arai, F. \& Ono, S. (2007a). Site-Selective Chemical Etching of Silicon Using Patterned Silver Catalyst. Electrochemistry Communications, Vol. 9, No. 4, pp. 535-539.

Asoh, H.; Arai, F. \& Ono, S. (2007b). Micro Patterning of Silicon by Chemical Etching Using Patterned Noble Metals as Catalyst. ECS Transactions, Vol. 6, No. 2, pp. 431-437.

Asoh, H.; Sakamoto, S. \& Ono, S. (2007c). Metal Patterning on Silicon Surface by Site-Selective Electroless Deposition through Colloidal Crystal Templating. Journal of Colloid and Interface Science, Vol. 316, No. 2, pp. 547-552.

Asoh, H. \& Ono, S. (2007d). Fabrication of ordered anodic nanoporous alumina layers and their application to nanotechnology, In: Electrocrystallization in Nanotechnology, G. Staikov, (Ed.), Chapter 7 pp. 138-166: Wiley-Vch Verlag GmbH \& Co. KGaA, ISBN 978-3-527-31545-4, Weinheim

Asoh, H.; Arai, F.; Uchibori, K. \& Ono, S. (2008). Pt-Pd-Embedded Silicon Microwell Arrays. Applied Physics Express, Vol. 1, No. 6, pp. 067003/1-067003/3.

Asoh, H.; Arai, F. \& Ono, S. (2009). Effect of Noble Metal Catalyst Species on the Morphology of Macroporous Silicon Formed by Metal-Assisted Chemical Etching. Electrochimica Acta, Vol. 54, No. 22, pp. 5142-5148.

Asoh, H. \& Ono, S. (2010). Nanohole arrays on silicon, In: Handbook of Nanophysics: Functional Nanomaterials, K. Sattler, (Ed.), Chapter 28 pp. 28-1 - 28-14 : Taylor \& Francis Books, Inc., ISBN 978-1-4200-7552-6, Boca Raton, FL, USA

Arai, F.; Asoh, H. \& Ono, S. (2008). Electroless Deposition of Noble Metal Nano Particles as Catalyst and Subsequent Micropatterning of Silicon Substrate by Wet Chemical Etching. Electrochemistry, Vol. 76, No. 3, pp. 187-190.

Chartier, C.; Bastide, S. \& Levy-Clement, C. (2008). Metal-assisted chemical etching of silicon in HF- $\mathrm{H}_{2} \mathrm{O}_{2}$. Electrochimica Acta, Vol. 53, No. 17, pp. 5509-5516.

Chattopadhyay, S.; Li, X. \& Bohn, P. W. (2002). In-plane control of morphology and tunable photoluminescence in porous silicon produced by metal-assisted electroless chemical etching. Journal of Applied Physics, Vol. 91, No. 9, pp. 6134-6140. 
Daniel, M. C. \& Astruc, D. (2004). Gold Nanoparticles: Assembly, Supramolecular Chemistry, Quantum-Size-Related Properties, and Applications toward Biology, Catalysis, and Nanotechnology. Chemical Reviews, Vol. 104, No. 1, pp. 293-346.

Deckman, H. W. \& Dunsmuir, J. H. (1982). Natural lithography, Applied Physics Letters, Vol. 41, No. 4, pp. 377-379.

Dweydari, A. W. \& Mee, C. H. B. (1975). Work function measurements on (100) and (110) surfaces of silver. Physica Status Solidi A, Vol. 27, No. 1, pp. 223-230.

Eastman, D. E. (1970). Photoelectric Work Functions of Transition, Rare-Earth, and Noble Metals, Physical Review B, Vol. 2, No. 1, pp. 1-2.

Flammini, R.; Wiame, F.; Belkhou, R.; Taleb-Ibrahimi, A.; Gregoratti, L.; Barinov, A.; Marsi, M. \& Kiskinova, M. (2004). Effect of annealing on the structure of the $\mathrm{Au} / \mathrm{Si}(111)-\mathrm{H}$ interface. Surface Science, Vol. 564, No. 1, pp. 121-130.

Ivanisevic, A. \& Mirkin, C. A. (2001). "Dip-Pen" Nanolithography on Semiconductor Surfaces. Journal of the American Chemical Society, Vol. 123, No. 32, pp. 7887-7889.

Jiang, P. \& McFarland, M. J. (2004). Large-Scale Fabrication of Wafer-Size Colloidal Crystals, Macroporous Polymers and Nanocomposites by Spin-Coating, Journal of the American Chemical Society, Vol. 126, No. 42, pp. 13778-13786.

Kleimann, P.; Linnros, J. \& Juhasz, R. (2001). Formation of three-dimensional microstructures by electrochemical etching of silicon, Applied Physics Letters, Vol. 79, No. 11, pp. 17271729.

Lehmann, V. \& Foll, H. (1990). Formation mechanism and properties of electrochemically etched trenches in n-type silicon. Journal of The Electrochemical Society, Vol. 137, No. 2, pp. 653-659.

Lehmann, V. (2002) Electrochemistry of Silicon, Wiley-Vch Verlag GmbH \& Co. KGaA, ISBN 3527-29321-3, Weinheim

Li, X. \& Bohn, P.W. (2000). Metal-assisted chemical etching in $\mathrm{HF} / \mathrm{H}_{2} \mathrm{O}_{2}$ produces porous silicon. Applied Physics Letters, Vol. 77, No. 16, pp. 2572-2574.

Maccarini, M.; Himmelhaus, M.; Stoycheva, S. \& Grunze, M. (2005). Characterisation and stability of hydrophobic surfaces in water. Applied Surface Science, Vol. 252, No. 5, pp. 1941-1946.

Matthias, S.; Muller, F.; Jamois, C.; Wehrspohn, R.B. \& Gosele, U. (2004). Large-area threedimensional structuring by electrochemical etching and lithography. Advanced Materials, Vol. 16, No. 23-24, pp. 2166-2170.

Motte, L.; Billoudet, F.; Lacaze, E.; Douin, J. \& Pileni, M. P. (1997). Self-Organization into 2D and 3D Superlattices of Nanosized Particles Differing by Their Size. The Journal of Physical Chemistry B, Vol. 101, No. 2, pp. 138-144.

Negishi, R.; Mochizuki, I. \& Shigeta, Y. (2006). Fabrication of uniform Au silicide islands on the Si(111)-(7×7) substrate, Surface Science, Vol. 600, No. 5, pp. 1125-1128.

Nieuwenhuys, B. E.; Bouwman, R. \& Sachtler, W. H. M. (1974). The changes in work function of group $\mathrm{Ib}$ and VIII metals on xenon adsorption, determined by field electron and photoelectron emission, Thin Solid Films, Vol. 21, No. 1, pp. 51-58.

Ono, S.; Oide, A. \& Asoh, H. (2007). Nanopatterning of Silicon with Use of Self-Organized Porous Alumina and Colloidal Crystals as Mask. Electrochimica Acta, Vol. 52, No. 8, pp. 2898-2904.

Ono, S.; Arai, F. \& Asoh, H. (2009). Micro-Patterning of Semiconductors by Metal-Assisted Chemical Etching through Self-Assembled Colloidal Spheres. ECS Transactions, Vol. 19, No. 3, pp. 393-402.

Ressel, B.; Prince, K. C.; Heun, S. \& Homma, Y. (2003). Wetting of Si surfaces by Au-Si liquid alloys, Journal of Applied Physics, Vol. 93, No. 7, pp. 3886-3892. 
Sakamoto, S.; Philippe, L.; Bechelany, M.; Michler, J.; Asoh, H. \& Ono, S. (2008). Ordered Hexagonal Array of Au Nanodots on Si Substrate Based on Colloidal Crystal Templating, Nanotechnology, Vol. 19, No. 40, pp. 405304/1-405304/6.

Sato, T.; Fujino, T. \& Hasegawa, H. (2006). Self-assembled formation of uniform InP nanopore arrays by electrochemical anodization in $\mathrm{HCl}$ based electrolyte, Applied Surface Science, Vol. 252, No. 15, pp. 5457- 5461.

Schmuki, P.; Lockwood, D. J.; Labbé, H. J. \& Fraser, J. W. (1996). Visible photoluminescence from porous GaAs, Applied Physics Letters, Vol. 69, No. 11, pp. 1620-1622.

Shi, H. \& Stampfl, C. (2008). Shape and surface structure of gold nanoparticles under oxidizing conditions, Physical Review B, Vol. 77, No. 9, pp. 094127/1-094127/9.

Sun, J.; Tang, C.; Zhan, P.; Han, Z.; Cao, Z. \& Wang, Z., (2010). Fabrication of Centimeter-Sized Single-Domain Two-Dimensional Colloidal Crystals in a Wedge-Shaped Cell under Capillary Forces, Langmuir, Vol. 26, No. 11, pp. 7859-7864.

Tsujino, K. \& Matsumura, M. (2005a). Boring deep cylindrical nanoholes in silicon using silver nanoparticles as a catalyst, Advanced Materials, Vol. 17, No. 8, pp. 1045-1047.

Tsujino, K. \& Matsumura, M. (2005b). Helical nanoholes bored in silicon by wet chemical etching using platinum nanoparticles as catalyst, Electrochemical and Solid-State Letters, Vol. 8, No. 12, pp. C193-C195.

Wang, S.; Yu, G. J.; Gong, J. L.; Zhu, D. Z. \& Xia, H. H. (2007). Large-area uniform nanodot arrays embedded in porous anodic alumina, Nanotechnology, Vol. 18, No. 1, pp. 015303/1-015303/4.

Wu, J. S.; Chen, Y. F.; Dhara, S.; Wu, C. T.; Chen, K. H. \& Chen, L. C. (2003). Interface energy of $\mathrm{Au}_{7} \mathrm{Si}$ grown in the interfacial layer of truncated hexagonal dipyramidal $\mathrm{Au}$ nanoislands on polycrystalline-silicon, Applied Physics Letters, Vol. 82, No. 25, pp. 4468-4470.

Yae, S.; Kawamoto, Y.; Tanaka, H.; Fukumuro, N. \& Matsuda, H. (2003). Formation of porous silicon by metal particle enhanced chemical etching in HF solution and its application for efficient solar cells, Electrochemistry Communications, Vol. 5, No. 8, pp. 632-636.

Yae, S.; Abe, M.; Fukumuro, N. \& Matsuda, H. (2008). Palladium enhanced etching of n-type silicon in hydrofluoric acid solution, Electrochemistry, Vol. 76, No. 2, pp. 144-146.

Yasukawa, Y.; Asoh, H. \& Ono, S. (2008a). Site-Selective Chemical Etching of GaAs through a Combination of Self-Organized Spheres and Silver Particles as Etching Catalyst, Electrochemistry Communications, Vol. 10, No. 5, pp. 757-760.

Yasukawa, Y.; Asoh, H. \& Ono, S. (2008b). Site-Selective Metal Patterning/Metal-Assisted Chemical Etching on GaAs Substrate through Colloidal Crystal Templating, ECS Transactions, Vol. 13, No. 3, pp. 83-92.

Yasukawa, Y.; Asoh, H. \& Ono, S. (2008c). GaAs Microarrays by Noble-Metal Assisted Chemical Etching, ECS Transactions, Vol. 16, No. 3, pp. 253-258.

Yasukawa, Y.; Asoh, H. \& Ono, S. (2009). Site-Selective Metal Patterning/Metal-Assisted Chemical Etching on GaAs Substrate through Colloidal Crystal Templating, Journal of The Electrochemical Society, Vol. 156, No. 10, pp. H777-H781.

Yasukawa, Y.; Asoh, H. \& Ono, S. (2010). Periodic GaAs Convex and Hole Arrays Produced by Metal-Assisted Chemical Etching, Japanese Journal of Applied Physics, Vol. 49, No. 11, pp. 116502/1-116502/4.

Yokoyama, T.; Asoh, H. \& Ono, S. (2010). Site-Selective Anodic Etching of InP Substrate Using Self-Organized Spheres as Mask, Physica Status Solidi A, Vol. 207, No. 4, pp. 943-946. 


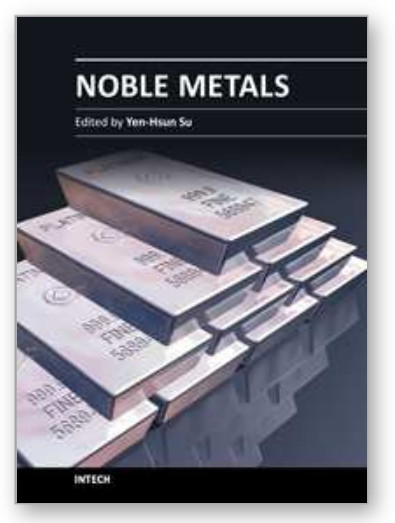

\author{
Noble Metals \\ Edited by Dr. Yen-Hsun Su
}

ISBN 978-953-307-898-4

Hard cover, 426 pages

Publisher InTech

Published online 01, February, 2012

Published in print edition February, 2012

This book provides a broad spectrum of insights into the optical principle, resource, fabrication, nanoscience, and nanotechnology of noble metal. It also looks at the advanced implementation of noble metal in the field of nanoscale materials, catalysts and biosystem. This book is ideal not only for scientific researchers but also as a reference for professionals in material science, engineering, nonascience and plasmonics.

\title{
How to reference
}

In order to correctly reference this scholarly work, feel free to copy and paste the following:

Sachiko Ono and Hidetaka Asoh (2012). Nano/Micro-Patterning of Semiconductors by Site Selective Chemical Etching Using Noble Metals as Catalyst, Noble Metals, Dr. Yen-Hsun Su (Ed.), ISBN: 978-953-307-898-4, InTech, Available from: http://www.intechopen.com/books/noble-metals/nano-micro-patterning-ofsemiconductors-by-site-selective-chemical-etching-using-noble-metals-as-cat

\section{INTECH}

open science | open minds

\author{
InTech Europe \\ University Campus STeP Ri \\ Slavka Krautzeka 83/A \\ 51000 Rijeka, Croatia \\ Phone: +385 (51) 770447 \\ Fax: +385 (51) 686166 \\ www.intechopen.com
}

\author{
InTech China \\ Unit 405, Office Block, Hotel Equatorial Shanghai \\ No.65, Yan An Road (West), Shanghai, 200040, China \\ 中国上海市延安西路65号上海国际贵都大饭店办公楼405单元 \\ Phone: +86-21-62489820 \\ Fax: $+86-21-62489821$
}


(C) 2012 The Author(s). Licensee IntechOpen. This is an open access article distributed under the terms of the Creative Commons Attribution 3.0 License, which permits unrestricted use, distribution, and reproduction in any medium, provided the original work is properly cited. 